\title{
Caracterización constructiva de las fábricas de tapia en las fortificaciones almohades del antiguo Reino de Sevilla
}

\section{Constructive characterization of historical rammed-earth walls in Almohad fortresses in the ancient Reign of Seville}

\author{
Jacinto Canivell \\ Amparo Graciani García \\ Escuela Técnica Superior de Ingeniería de Edificación. Universidad de Sevilla \\ e-mail: jacanivell@us.es, agracianig@us.es
}

\begin{abstract}
RESUMEN
La mayor parte del patrimonio monumental andaluz construido en tierra corresponde a edificaciones militares levantadas en tapial entre los siglos XII al XV. Las del Antiguo Reino de Sevilla constituyen un grupo muy significativo, muchas de las cuales han sido objeto de intervenciones en las últimas décadas. En este trabajo se determinan, analizan y evalúan los principales rasgos técnicos y métricos de las fábricas de tapia de este ámbito espacial de época almohade, con un triple fin: aportar directrices que garanticen una restauración coherente y respetuosa con el bien patrimonial, avanzar en el conocimiento de los usos históricos de esta técnica constructiva y plantear hipótesis en relación a fábricas de adscripción cronológica incierta. Para ello, se implementa la metodología propuesta por los autores en trabajos precedentes.
\end{abstract}

Palabras clave: Técnica constructiva; cronología; arquitectura militar; siglos XII-XIV.

\begin{abstract}
Most of the Andalusian earthen heritage corresponds to military rammed earth buildings set up between XII and XV centuries. Those corresponding to the Ancient Reign of Seville are the most outstanding group, in which a great number of them have been restored during the last decades. This research aims to state, analyze and assess the main technical and dimensional features of rammed earth walls in this area at the Almohad period. This research is focused on three objectives: provide guidelines in order to assure more consistent and respectful heritage restorations, advance the understanding of historical uses of this constructive technique and state hypothesis about walls of uncertain origin. To that end an assessment methodology proposed by the authors will be implemented.
\end{abstract}

Keywords: Constructive techniques; chronology; military architecture; XII-XIV Centuries.

Recibido: 19-06-2014. Aceptado: 10-12-2014.

Cómo citar este artículo / Citation

Canivell, J. y Graciani García, A. 2015: "Caracterización constructiva de las fábricas de tapia en las fortificaciones almohades del antiguo Reino de Sevilla", Arqueología de la Arquitectura, 11: e025. doi: http://dx.doi.org/10.3989/arq.arqt.2015.003

\section{Copyright}

(C) 2015 CSIC. Este es un artículo de acceso abierto distribuido bajo los términos de la licencia Creative Commons Attribution-Non Commercial (by-nc) Spain 3.0. 


\section{INTRODUCCIÓN}

La arquitectura fortificada de tapia en España es la mejor muestra de la importancia que esta técnica adquirió en su historia, tanto en grandes construcciones monumentales como en la arquitectura doméstica tradicional. Su consideración, tratamiento e interés han evolucionado en paralelo a los del resto de la construcción en tierra. De hecho, tras su despreocupación y abandono desde el siglo XIX, en las últimas tres décadas esta tipología ha sido objeto de un mayor interés por parte de los investigadores. A ello ha contribuido el impulso que desde mediados del siglo XX entidades nacionales e internacionales han dado a la construcción en tierra, pero también la necesidad de dar un soporte científico-técnico a intervenciones de restauración y rehabilitación.

Aunque en la Península Ibérica existen muchos ejemplos de edificaciones militares califales o taifas de tapia, la mayoría fueron levantadas entre los siglos XII y XV. Unas fueron ejecutadas durante la época de las dinastías norteafricanas (siglo XII y primera mitad del XIII), momento en que la tapia se impuso a la mampostería, tanto en grandes poblaciones como en gran parte de las líneas fronterizas donde resultaba muy apropiada por su bajo coste y rapidez de construcción. Otras son posteriores a la Reconquista, evidenciando algunas novedades y variaciones respecto a las almohades.

Las actuales provincias de Sevilla, Huelva, Cádiz y el sur de la de Badajoz, es decir el área que abarcó el antiguo Reino de Sevilla, atesora una parte importante de este patrimonio. De hecho, el SIPHA (Sistema de Información de Patrimonio Histórico de Andalucía) recoge setenta fortificaciones medievales en tapia correspondientes a este ámbito geográfico y al intervalo cronológico estudiado (siglos XII-XV). La importancia que la técnica adquirió tanto con los almohades en el entorno de la capital, Isbiliya, y en su frontera con el reino de Castilla, y posteriormente en la frontera con el reino de nazarí de Granada, justifican tal profusión. Sin embargo, son muy contadas las que, indiscutiblemente y con rigurosidad, se adscriben a época almohade.

A fin de obtener una caracterización de las fábricas analizadas que contribuya a su datación, los autores de estas páginas han aplicado sobre estas fortificaciones la metodología de evaluación que, para el estudio de este sistema constructivo, de sus lesiones y sus causas y sus vulnerabilidades, han propuesto en el marco del proyecto BIA-2004 1094, del Plan Nacional I+D+i del Ministerio de Ciencia e Innovación, centrándose en concreto en los parámetros constructivos de dicha metodología (Graciani 2005; Canivell 2012; Canivell y Graciani 2012). El conocimiento de las características constructivas resultado de este estudio debería además ser considerado a la hora de intervenir sobre estas construcciones.

\section{ESTADO DE LA CUESTIÓN}

El impulso que en las tres últimas décadas del siglo $\mathrm{XX}$ experimentó la historiografía sobre castillos y arquitectura defensiva, llegó al ámbito español tras los ochenta y sobre todo en los noventa (Bazzana 1980; López 1994; Acién 1995). En este contexto se celebró en 1994 el I Congreso de Castellología Ibérica (cuyas actas se publicaron en 1998) y se desarrollaron algunos proyectos nacionales de investigación, como el PB951151 ("Los asentamientos medievales en la frontera entre el Reino de Granada y Castilla, siglos XIII-XV, Ministerio de Educación 1996-1999). Las primeras publicaciones al respecto se centraron en la organización del territorio a partir de fuentes historiográficas y cronísticas, perspectiva también aplicada a las fortificaciones del periodo andalusí (Azuar 1994, 1995; Iglesia 1995; Malpica 2003).

En paralelo, se evidenció un interés por la cultura almohade, que con los años germinaría en un proyecto de investigación promovido por la Casa de Velázquez, el Departamento de Estudios Árabes (Instituto de Filología, CSIC, Madrid) y la UMR 5648 (CNRS-UniversitéLumiére-Lyon 2) y, puntualmente, por la Université de Toulouse-LeMirail, y en la realización de tres seminarios entre 2000 y 2002 (Cressier, Fierro y Molina 2005).

La confluencia de ambos intereses (la arquitectura defensiva y la cultura almohade) propició que en nuestro país aparecieran algunas publicaciones sobre construcciones militares almohades, cuestión hasta el momento sólo abordada por Torres Balbás (1960a, 1960b). Entre ellas destacan algunas de Valor (2004a y 2004b), sin duda la máxima especialista en la materia. Por la importancia de la tapia en las construcciones defensivas almohades, estas primeras publicaciones abordaban la técnica bien a partir del estudio de las fábricas (Gurriarán y Sáez 2002; Azuar 2004 y 2005) o bien de los revestimientos con falsos despieces (Lozano, Menéndez, Azuar y Llopis 1996; Azuar, Llopis, Lozano y Menéndez 1998). 
Desde 2005, las investigaciones sobre las fábricas de tapia en la arquitectura defensiva han proliferado en España con una intensidad superior a la de otros entornos geográficos (Jaquin, Augarde y Gerrard 2008). En muchos casos, estos trabajos resultan de estudios previos en obras de restauración realizados en construcciones defensivas, unos estudios que son cada vez más frecuentes aunque no habituales. En consecuencia, la técnica de la tapia en la arquitectura fortificada andalusí ha sido así estudiada por autores como F. J. López (1996, 1999, 2012), Azuar (1995, 2004), Gurriarán y Sáez (2002), Graciani (2005, 2008-2009, 2009), Graciani y Tabales (2008) y Canivell (2012).

También se han realizado estudios zonales; en concreto, se han abordado las particularidades de las fortificaciones peninsulares en Andalucía Occidental y Oriental, Murcia y Valencia, en algunos casos conjugando el estudio constructivo con el análisis de caracterización material (De la Torre, Pardo y Rodríguez 1996; Ontiveros, Valverde y Sebastián 1996 y 2006; Graciani, Tabales, Alejandre, Barrios, Rodríguez y Ponce 2005).

Entre los relativos a Andalucía Occidental, ámbito geográfico objeto de estas páginas, destacan los de Graciani (2008, 2008-2009, 2009), Canivell y González (2012), Jiménez y Pérez (2012), Utrera y Tabales (2009), Graciani, Martín, Mora, Alejandre y Canivell (2012) y Barrios, Graciani y Núñez (2012). La mayor parte de ellos provienen de los resultados obtenidos durante el desarrollo del proyecto de investigación BIA2004 1092, del Plan Nacional de Investigación I+D+I, durante cuyo desarrollo se estableció una metodología para determinar los procesos constructivos a partir de la caracterización de las fábricas, considerando también las circunstancias históricas, sociales y culturales de la construcción. Entre los estudios de Andalucía Oriental, destacan los trabajos de Martín (2005), Martín y Martín Civantos (2011) y López Osorio (2012); entre los dedicados a Murcia y Valencia, los de López (1999) Mileto, Vegas, Cristini y García (2012) y Soler (2009).

Pese a los avances de los últimos años, quedan importantes lagunas de investigación. Las metodologías de caracterización deben aplicarse a construcciones de periodos concretos, a fin de determinar los rasgos constructivos propios de los diferentes ámbitos geográficos y etapas históricas. Para ello, han de considerarse tan sólo aquellas edificaciones sobre cuya datación los especialistas (arqueólogos, documentalistas y medievalistas) tengan certeza, debiendo obviarse aquellos ejemplos de datación imprecisa o dudosa.
Los resultados de estas investigaciones podrán ser de aplicación en aquellas restauraciones científicas que se fundamenten en criterios de intervención compatibles y coherentes con las fábricas primigenias (Mileto, Vegas y López 2011; Maldonado y Vela 2011: 76; López 2012: 26). Al mismo tiempo, facilitarán a los historiadores la datación de fábricas, y en ocasiones, revisar las ya adscritas.

\section{OBJETIVOS}

En estas páginas se analizan las particularidades de una serie de fábricas de tapia de edificaciones defensivas del SO peninsular que están sujetas a parámetros similares, con el objeto de aportar conocimientos que puedan servir de apoyo en restauraciones de construcciones militares almohades en tapia.

Valorar cómo estas novedades se fueron adaptando a la tradición previa y cuál fue su proceso de propagación por las distintas áreas territoriales nos permitirá determinar la posible existencia de particularidades zonales o tipológicas con relación a la técnica constructiva, los medios auxiliares, y cuestiones métricas y materiales.

A tal fin, se considerarán como objeto de estudio las construcciones militares porque fueron este tipo de edificaciones, y no las domésticas, las que por el mayor espesor de los muros resultaron más favorables a la adopción de las innovaciones tecnológicas de los encofrados islámicos. Por ejemplo, la sustitución de la aguja pasante (y en ocasiones recuperable) por dos medias agujas (ancladas a la masa con clavos de madera) conllevaría otras novedades en el conjunto del encofrado respecto al de la construcción doméstica que, por el contrario, se resuelve al modo tradicional (Doat, Hays, Houben, Matuk y Vitoux 1991: 21); así, se mantiene el costal que, sobre cada aguja, se aplica al exterior de los tableros a fin de fijar la posición de los encofrados y se sustituye el codal que lo fija por puntales dispuestos en el interior del encofrado (Fig. 1).

Por lo tanto, los objetivos de este trabajo son: (1) determinar los rasgos constructivos y los condicionantes propios y exógenos que son característicos de las fábricas militares de tapia en el ámbito espacio-temporal de estudio y que pueden ser las bases argumentales para intervenciones más coherentes y, con ello, (2) proponer una adscripción temporal de las fábricas de cronología incierta en función de las singularidades constructivas asociadas a cada periodo. 

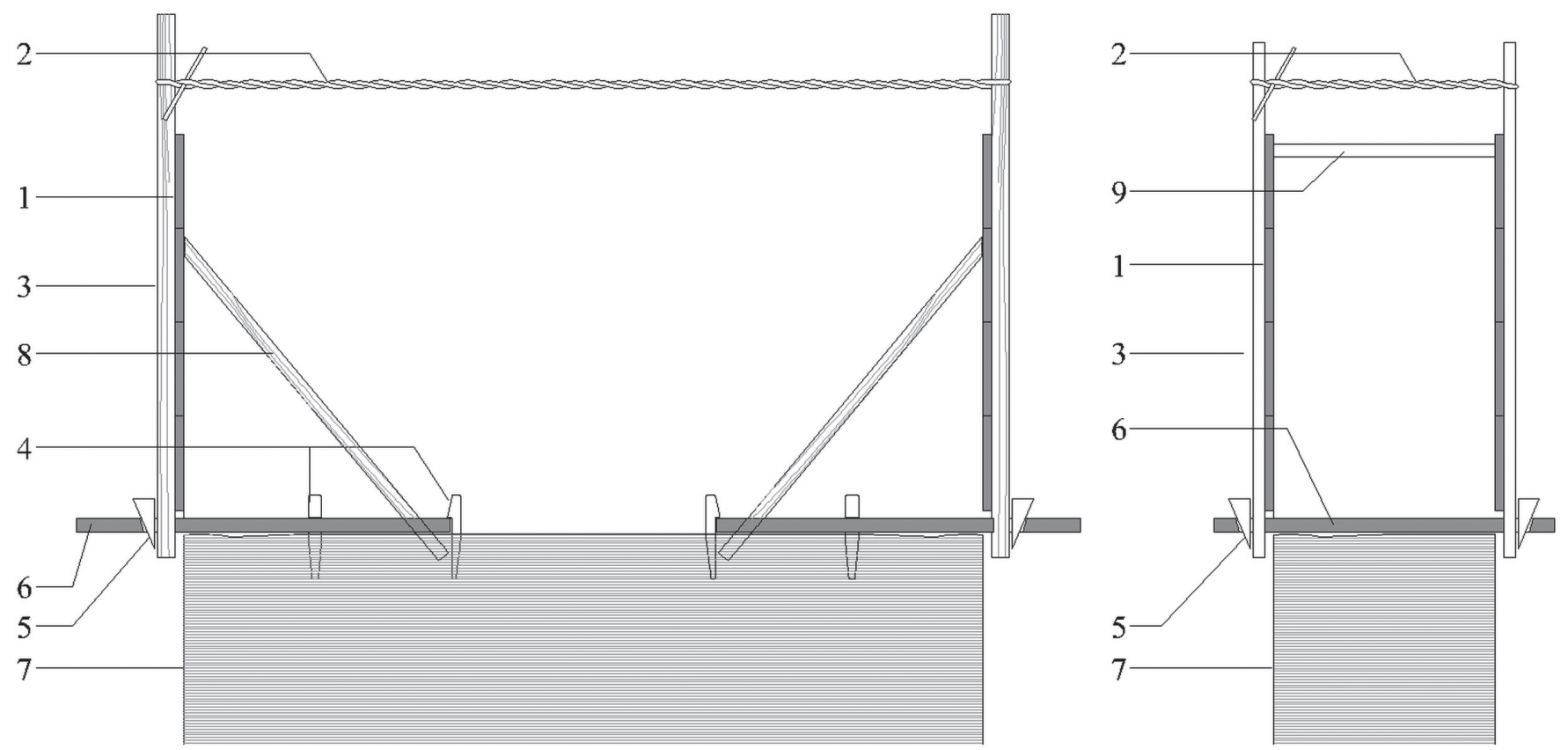

Fig. 1. Comparación entre una sección tipo de un muro de tapia militar propuesto por López Osorio (2012: 30) (izq.) y otro tradicional (der.) tal y como proponen Doat, Hays, Houben, Matuk y Vitoux (1991: 13): 1. Encofrado; 2. Cuerdas; 3. Costal; 4. Clavos; 5. Cuña; 6. Aguja; 7. Tapia; 8. Puntal; 9. Codal.

\section{CASOS DE ESTUDIO Y METODOLOGÍA DE ANÁLISIS}

De forma intencionada, no ha sido abordada la totalidad de las construcciones militares que de dichas provincias quedan recogidas en SIPHA, pues a fin de obtener datos certeros y fiables, sólo se han considerado aquellas que no presentan alteraciones en las características constructivas originales de sus fábricas, descartando tanto las excesivamente dañadas como las alteradas por intervenciones previas.

Por lo tanto, en esta investigación, se han analizado un total de treinta y cinco edificaciones militares realizadas total o parcialmente con fábricas de tapia entre los siglos XII al XV, y emplazadas en su mayor parte en el antiguo Reino de Sevilla, a excepción de dos en su entorno más inmediato, en concreto del Algarbe portugués (Castillo de Paderne) y la actual provincia de Badajoz (Castillo de Reina), ambos de origen almohade. De estas treinta y cinco edificaciones, quince corresponden con certeza a época a almohade, nueve a cristianas, siendo las once restantes de adscripción incierta (Fig. 2 ); entre todas ellas se han registrado cuarenta y cuatro fábricas de tapia, de las cuales veinticuatro son almohades, nueve cristianas y once de datación incierta. Las adscripciones cronológicas consideradas para los casos analizados no han sido establecidas por los autores de estas páginas; se fundamentan en las investigaciones más recientes al respecto (Aguilar 2000; Almagro 2013; Azuar 2004; Bellido 2008a, 2008b; Catarino 1997; Hernández, Sancho y Collantes 1955; García Fitz 2008; Graciani 2008-2009; Graciani, Martín, Mora, Alejandre y Canivell 2012; Guerrero 1990; Pérez, Campos y Gómez 2000; Valor 2004a, 2004b).

En general, estos trabajos no recogen estudios estratigráficos que permitan puntualizar qué paramentos o tramos corresponden a qué etapa, lo que dificultó la elección de los tramos a estudiar por ser frecuentes las superposiciones de fábricas. Por ello, para realizar los estudios de cada caso se han seleccionado tramos concretos (que se detallan en la figura 3), procurando escoger paños de fábricas homogéneas, sin una excesiva estratificación paramental.

A priori, el estudio constructivo que se aporta se fundamenta en los datos obtenidos en quince de estas treinta y cinco edificaciones, en concreto en aquellas que la historiografía más reciente adscribe al periodo almohade. El estudio de las nueve construcciones que son claramente consideradas cristianas, permitirá contrastar las particularidades constructivas almohades que se proyectaron o, por el contrario, desaparecieron tras la Reconquista. El análisis de estos casos aportará 


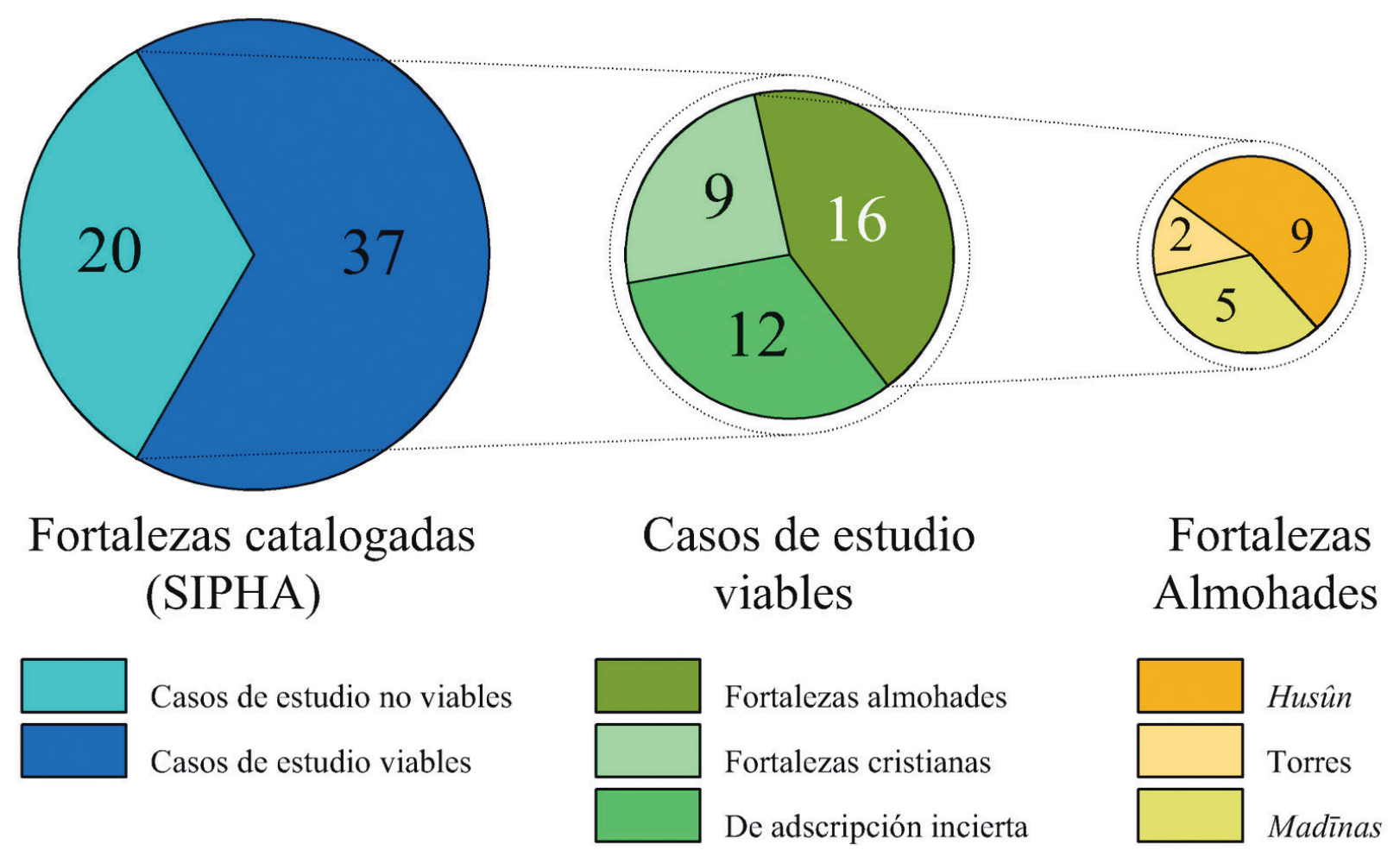

Fig. 2. Distribución de los casos de estudio de las fortalezas según su viabilidad (gráfica izq.), a su posible vinculación cronológica (gráfica central) y a su tipología militar (gráfica der.).

fundamentos constructivos para una datación preliminar de las once construcciones restantes, que responden en unos casos a ampliaciones de estructuras realizadas en algún momento posterior a la Reconquista, pero de las que se desconoce qué paramentos corresponden a cada fase, $y$ en otros a fortificaciones realizadas ex novo pero de dudosa vinculación temporal.

Las quince edificaciones almohades eje de este estudio no pueden ser comparables per se, en igualdad de condiciones; deben considerarse las diferentes tipologías que, en función de las unidades de poblamiento (Vigueras 2004:10) existían en el momento (Valor 2004a), es decir, tanto murallas y cercas urbanas (madinas), como castillos (husun) — grandes y pequeños y torres (atalayas o almenaras, de alquería y de delimitación de términos), pero también una diversidad de parámetros (cronológicos, geográficos y geopolíticos) que pudieron condicionar diferencias en el proceso de implantación en el SO de la Península Ibérica de las novedades constructivas que las tribus norteafricanas aportaron a la ejecución de la tapia, haciendo que en unas construcciones se adoptaran las soluciones novedosas pero no en otras.

Así, las construcciones almohades de mediados del siglo XII parecen no haber incorporado aún las novedades constructivas que en su segunda mitad (y ya sobre todo en la primera del siglo XIII) constituirán las verdaderas aportaciones de esta cultura a la técnica de ejecución de tapia. La situación geográfica condicionaría el proceso de expansión de las novedades, favorecido en aquellas zonas estratégicas y de fácil acceso (próximas a caminos o rutas rurales en los cauces fluviales) y, por el contrario, dificultado en zonas montañosas o fronterizas (como parte de la frontera norte del Reino Almohade y la Banda morisca).

La envergadura de las principales murallas y cercas urbanas de la segunda mitad del siglo XII y la primera del siglo XIII hizo que, para dar respuesta a sus necesidades constructivas, se realizaran mejoras en los encofrados. Por ello, estas construcciones pueden ser consideradas fósiles directores de referencia, desde las cuales, las novedades técnicas se difundirían, gracias a la importancia de estos centros de población, generalmente bien comunicados y asociados a cauces fluviales, caminos y vías terrestres.

En concreto, se han analizado cinco madinas o cercas urbanas, nueve husun (o castillos y alquerías) y una torre. Las cercas urbanas almohades analizadas han sido las de Sevilla (Valor 2004a: 147), Niebla (Pérez, Campos 
y Gómez 2000: 116), Jerez de la Frontera (Aguilar 2000; Azuar 2004: 61) y dos que la historiografía acepta como construidas de nueva planta por los almohades; en concreto, las de Écija (Valor 2004a: 152; Hernández, Sancho y Collantes 1955) y Marchena (Bellido 2008a, 2008b; Graciani 2008-2009: 16), poblaciones que fueron engrandecidas y consolidadas como madīnas en época almohade y en las terceras taifas. Considerando la fiabilidad de los datos obtenidos, ya que algunos de los tramos han sido alterados con el tiempo, este estudio se centra en la información obtenida en puntos concretos de las murallas de Écija (en torres y lienzos de la Plaza de Colón y en sendos tramos de la calle Merinos), Marchena (en el tramo del Mirador y El Parque, incluyendo el lienzo y la torre de la Alcazaba), Sevilla (los lienzos de los tramos de la Macarena, el Jardín del Valle, el Callejón del Agua, de la Casa de la Moneda y algunos tramos del sector SO, además de la Torre del Oro), en Niebla (lienzos de Puerta del Embarcadero) y Jerez de la Frontera (lienzo Norte).

Los husun (alcázares y alquerías) que la historiografía precedente considera claramente almohades (bien reconstruidos o ex novo) y que, en consecuencia, han

\begin{tabular}{|c|c|c|c|c|c|}
\hline Localización & Denominación & Tipología & Elemento analizado & Latitud & Longitud \\
\hline Albaida del Aljarafe & $\begin{array}{l}\text { Torre mocha de Don } \\
\text { Fadrique }\end{array}$ & Hisn & Torre & $37^{\circ} 25^{\prime} 41.31^{\prime \prime} \mathrm{N}$ & $6^{\circ} 10^{\prime} 1.76^{\prime \prime} \mathrm{O}$ \\
\hline Carmona & $\begin{array}{l}\text { Alcázar del Rey Don } \\
\text { Pedro }\end{array}$ & Hisn & Lienzo externo oeste & $37^{\circ} 28^{\prime} 24.17^{\prime \prime} \mathrm{N}$ & $5^{\circ} 37^{\prime} 59.20^{\prime \prime O}$ \\
\hline Dos Hermanas & $\begin{array}{l}\text { Hacienda de los } \\
\text { Quintos }\end{array}$ & Hisn & Torre & $37^{\circ} 20^{\prime} 4.36^{\prime \prime} \mathrm{N}$ & $5^{\circ} 55^{\prime} 18.31 " \mathrm{O}$ \\
\hline Guillena & Castillo de Guillena & Hisn & Lienzos tramo sur & $37^{\circ} 32^{\prime} 24.16^{\prime \prime} \mathrm{N}$ & $6^{\circ} 37.28^{\prime \prime O}$ \\
\hline Lora del Rio & Castillo de Lora del Río & Hisn & Lienzos y restos de torres & $37^{\circ} 39^{\prime} 10.81^{\prime \prime} \mathrm{N}$ & $5^{\circ} 32^{\prime} 6.98^{\prime \prime} \mathrm{O}$ \\
\hline Paderne & Castillo de Paderne & Hisn & Lienzos sector noroeste & $37^{\circ} 9 ' 26.30^{\prime \prime N}$ & $8^{\circ} 12^{\prime} 1.18^{\prime \prime O}$ \\
\hline Reina (Badajoz) & Alcazaba de Reina & Hisn & Lienzos y torres sector $\mathrm{SO}$ & $38^{\circ} 11^{\prime} 22.98^{\prime \prime} \mathrm{N}$ & $5^{\circ} 57^{\prime} 24.54^{\prime \prime} \mathrm{O}$ \\
\hline Sanlúcar la Mayor & $\begin{array}{l}\text { Muralla de Sanlúcar la } \\
\text { Mayor }\end{array}$ & Hisn & $\begin{array}{l}\text { Lienzos sector Iglesia de } \\
\text { S. Pedro }\end{array}$ & $37^{\circ} 22^{\prime} 58.92^{\prime \prime} \mathrm{N}$ & $6^{\circ} 12^{\prime} 16.53 " \mathrm{O}$ \\
\hline $\begin{array}{l}\text { San Juan de } \\
\text { Aznalfarache }\end{array}$ & $\begin{array}{l}\text { Muralla de San Juan de } \\
\text { Aznalfarache }\end{array}$ & Hisn & $\begin{array}{l}\text { Lienzo y torre en } \mathrm{Cl} \\
\text { Monumento }\end{array}$ & $37^{\circ} 21^{\prime} 53.69^{\prime \prime} \mathrm{N}$ & $6^{\circ} 1^{\prime} 43.41 " \mathrm{O}$ \\
\hline \multirow{7}{*}{ Sevilla } & $\begin{array}{l}\text { Muralla de Sevilla. } \\
\text { Tramo de la Macarena }\end{array}$ & Madinas & $\begin{array}{l}\text { Lienzos entre S. } \\
\text { Hermenegildo-portillo } 2\end{array}$ & $37^{\circ} 24^{\prime} 7.01^{\prime \prime N}$ & $5^{\circ} 59^{\prime} 11.55^{\prime \prime O}$ \\
\hline & $\begin{array}{l}\text { Muralla de Sevilla. } \\
\text { Tramo de la Macarena }\end{array}$ & Madinnas & $\begin{array}{l}\text { Lienzos entre } \\
\text { Pta. Macarena - portillo } 1\end{array}$ & $37^{\circ} 24^{\prime} 10.33^{\prime \prime N}$ & $5^{\circ} 59^{\prime} 17.91 " \mathrm{O}$ \\
\hline & $\begin{array}{l}\text { Muralla de Sevilla. } \\
\text { Jardines del Valle }\end{array}$ & Madinas & $\begin{array}{l}\text { Torres y lienzos } \\
\text { Convento del Valle }\end{array}$ & $37^{\circ} 23^{\prime} 43.59^{\prime \prime} \mathrm{N}$ & $5^{\circ} 59^{\prime} 1.62^{\prime \prime O}$ \\
\hline & $\begin{array}{l}\text { Muralla de Sevilla. } \\
\text { Callejón del Agua }\end{array}$ & Madinas & $\begin{array}{l}\text { Lienzos en } \\
\text { Callejón del Agua }\end{array}$ & $37^{\circ} 23^{\prime} 4.72^{\prime \prime} \mathrm{N}$ & $5^{\circ} 59^{\prime} 20.66^{\prime \prime} \mathrm{O}$ \\
\hline & $\begin{array}{l}\text { Muralla de Sevilla. } \\
\text { Casa de la Moneda }\end{array}$ & Madīnas & $\begin{array}{l}\text { Lienzos en edificio } \\
\text { Previsión Española }\end{array}$ & $37^{\circ} 22^{\prime} 58.46^{\prime \prime} \mathrm{N}$ & $5^{\circ} 59^{\prime} 43.43^{\prime \prime} \mathrm{O}$ \\
\hline & $\begin{array}{l}\text { Muralla de Sevilla. } \\
\text { Torre del Oro }\end{array}$ & Madīnas & Torre Albarrana & $37^{\circ} 22^{\prime} 57.16^{\prime \prime} \mathrm{N}$ & $5^{\circ} 59^{\prime} 46.38^{\prime \prime} \mathrm{O}$ \\
\hline & $\begin{array}{l}\text { Muralla de Sevilla. } \\
\text { Jardines de Murillo }\end{array}$ & Madinas & Lienzos y torres & $37^{\circ} 23^{\prime} 5.94^{\prime \prime} \mathrm{N}$ & $5^{\circ} 59^{\prime} 17.12^{\prime \prime} \mathrm{O}$ \\
\hline \multirow{3}{*}{ Écija } & Tramo Plaza Colón & Madinas & Torre & $37^{\circ} 32^{\prime} 39.08^{\prime \prime} \mathrm{N}$ & $5^{\circ} 5^{\prime} 0.74^{\prime \prime O}$ \\
\hline & Tramo Calle Merinos 1 & Madinas & Lienzos y torre & $37^{\circ} 32^{\prime} 40.75^{\prime \prime} \mathrm{N}$ & $5^{\circ} 4^{\prime} 45.27 " \mathrm{O}$ \\
\hline & Tramo Calle Merinos 2 & Madinas & Lienzos y torre & $37^{\circ} 32^{\prime} 40.45^{\prime \prime} \mathrm{N}$ & $5^{\circ} 4^{\prime} 36.44 " \mathrm{O}$ \\
\hline Jerez de la Frontera & Murallas de Jerez & Madinas & Lienzo norte & $36^{\circ} 41^{\prime} 16.19^{\prime \prime} \mathrm{N}$ & $6^{\circ} 8 ' 32.52 " \mathrm{O}$ \\
\hline \multirow[b]{2}{*}{ Marchena } & Alcazaba de Marchena & Madinas & Torre & $37^{\circ} 19^{\prime} 59.92^{\prime \prime} \mathrm{N}$ & $5^{\circ} 25^{\prime} 3.31^{\prime \prime O}$ \\
\hline & $\begin{array}{l}\text { Muralla tramo Ctra. } \\
\text { Carmona }\end{array}$ & Madinas & Lienzos y torre & $37^{\circ} 20^{\prime} 4.02^{\prime \prime} \mathrm{N}$ & $5^{\circ} 24^{\prime} 57.86^{\prime \prime} \mathrm{O}$ \\
\hline Niebla & Murallas de Niebla & Madinas & $\begin{array}{l}\text { Lienzos sector Pta. del } \\
\text { Embarcadero }\end{array}$ & $37^{\circ} 21^{\prime} 36.31^{\prime \prime} \mathrm{N}$ & $6^{\circ} 40^{\prime} 34.20^{\prime \prime} \mathrm{O}$ \\
\hline Olivares & Torre de San Antonio & Torre & Torre & $37^{\circ} 28^{\prime} 39.91^{\prime \prime N}$ & $6^{\circ} 11^{\prime} 1.32 " \mathrm{O}$ \\
\hline Peñaflor & Castillo de Almenara & Torre & Torre & $37^{\circ} 45^{\prime} 35.47^{\prime \prime} \mathrm{N}$ & $5^{\circ} 22^{\prime} 31.68^{\prime \prime} \mathrm{O}$ \\
\hline
\end{tabular}

Fig. 3. Relación de los objeto de estudio de las fábricas de tapia correspondientes a los quince casos de estudio almohades. 
sido objeto de este estudio se encuentran el Castillo de Sanlúcar la Mayor (Valor 2004a: 157), la Muralla de San Juan de Aznalfarache (Valor 2004a: 155), el Castillo de Lora del Río, el de Guillena (Valor 2004a: 147), la Alcazaba de Reina en Badajoz (Valor 2004b: 688), la torre (de alquería) de Quintos (Valor 2004a: 158), el Alcázar del Rey Don Pedro en Carmona (Almagro 2013: 35), el castillo de Paderne (Catarino 1997: 449) y la Torre Mocha o de Don Fadrique en Albaida del Aljarafe (Graciani, Martín, Mora, Alejandre y Canivell 2012). Entre las torres (atalayas o almenaras, de alquería y de delimitación de términos) destaca la de San Antonio en Olivares (Valor 2004a: 146). Los puntos referenciados en este estudio se recogen en las figuras 3 y 4.

Como se ha indicado, las comparaciones entre las soluciones almohades y cristianas, se establecen a partir de la toma de datos realizada sobre aquellas edificaciones que la historiografía no duda en considerar cristianas (nueve casos); en concreto, los Castillos de Alhonoz, Mairena del Alcor, Estepa, del Hierro, Setefilla, Los
Molares y Utrera (Valor 2004b: 692 y 696), además de la Torre de Alcantarilla (Valor 2004b: 692) y la de los Herberos (Guerrero 1990). En el tercer grupo, correspondiente a las construcciones de adscripción incierta, con núcleos islámicos ampliados o reformados (con un alcance indefinido) en época cristiana y de los que no hay certeza de qué paramentos corresponden a cada uno, se encuentran seis husun (en concreto, los castillos de Alcalá de Guadaira (García Fitz 2008: 235 y 251; Valor 2004b: 695), Castillo de las Guardas, Hornachos, Lebrija, Paredones (Osuna), y Tejada (Escacena del Campo), cuatro torres (las de la Dehesilla en Aznalcóllar, la Membrillera o Membrilla en Carmona, la Corchuela en Dos Hermanas, Almenara en Peñaflor) y la madīna de Utrera.

Este trabajo de investigación se ha realizado aplicando la metodología de análisis constructivo y evaluación propuesta por Canivell (2012), según los parámetros técnicos y métricos de la figura 5. Esta metodología se fundamenta en unos estudios previos de caracterización apoyados en una toma de datos in situ (anamnesis)

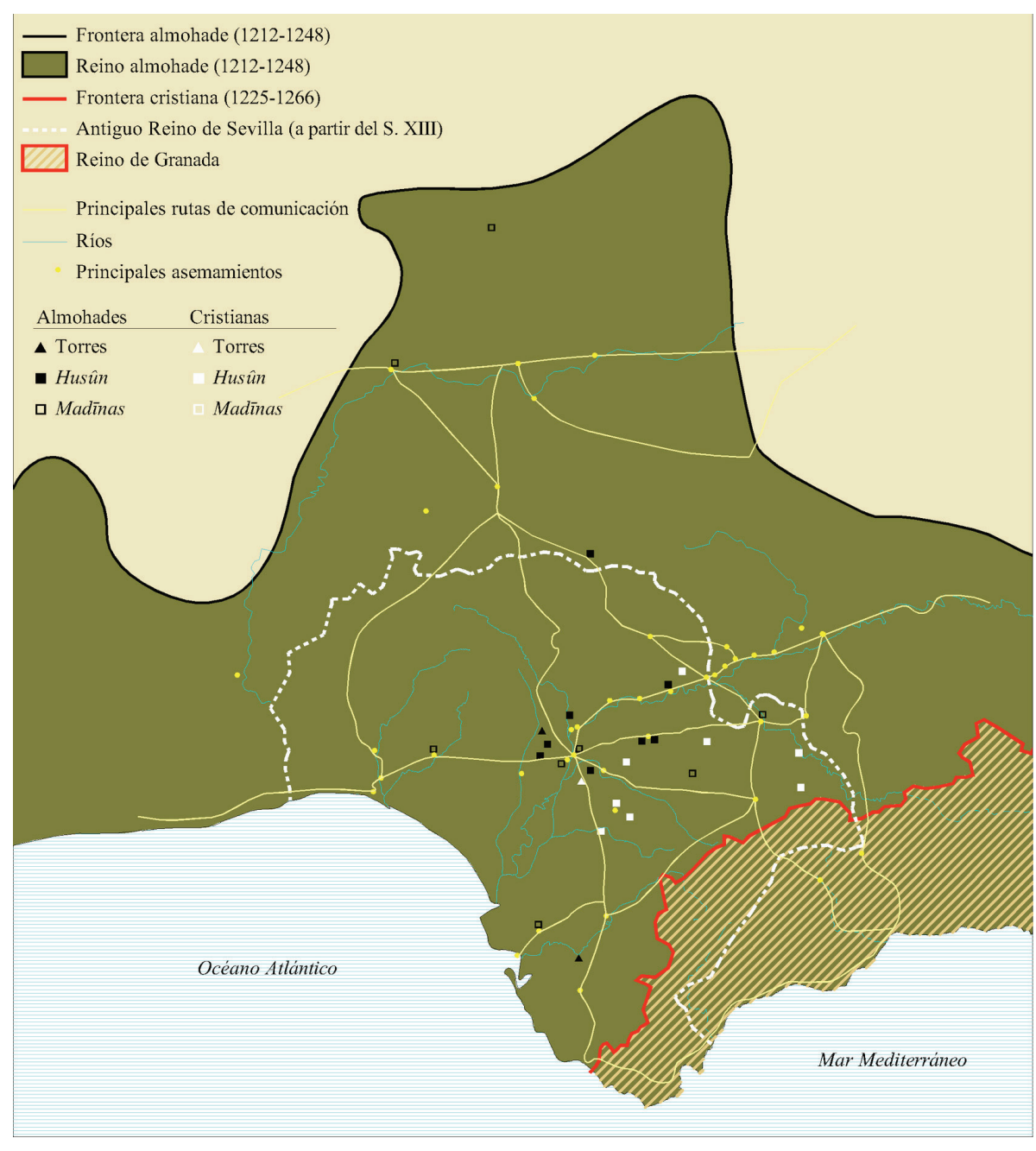

Fig. 4. Distribución geográfica de los casos de estudio de cronología almohade, cristiana e incierta. Vías de comunicación (Díaz, Olmedo y Clavero 2009).

Frontera con Reino de Granada y Reino de Sevilla (García Cortázar 2007). Frontera almohade (Ubieto 1984). 
de un amplio grupo de parámetros y cualidades de las fábricas que pueden agruparse en tres categorías de caracterización: la constructiva (técnica, dimensional y material), la caracterización de daños (estructurales, materiales o de superficie y, para cada uno de las causas), y la de vulnerabilidades (considerando vulnerabilidad al agua, física y estructural). En el análisis realizado, no se han tomado en cuenta los parámetros constructivos que definen el material, ya que a fecha de hoy no se dispone de suficientes de datos objetivos obtenidos a partir de ensayos materiales, careciendo de la relevancia necesaria las observaciones cualitativas con que se cuenta.

Partiendo de una toma de datos in situ de los parámetros técnicos y métricos propuestos, que han quedado registrados en una base de datos, a fin de conseguir los objetivos marcados, la investigación ha precisado acometer tres tareas: realizar un estudio constructivo de las fábricas seleccionadas; un análisis comparativo de los rasgos relevantes en fábricas almohades y cristianas con el fin de distinguir las singularidades de cada periodo histórico; y en tercer lugar, categorizar los parámetros constructivos según su relevancia en cada periodo analizado.

\section{RESULTADOS Y DISCUSIÓN}

\section{Caracterización constructiva}

La selección de parámetros para la caracterización constructiva de los casos seleccionados aporta novedades sobre los propuestos por otros autores (López 1999; Gurriarán y Sáez 2002; Martín 2005; Graciani y Tabales 2008; Canivell 2012; López Osorio 2012), incorporando aquellos que se entienden son relevantes para el análisis y la definición de la fábrica y que en consecuencia deben condicionar la intervención patrimonial (Fig. 5).

Estructural de la fábrica. A partir de las variaciones observadas en los distintos recursos constructivos (mechinales, verdugadas o encadenados) Graciani y Tabales (2008) establecen la existencia en Andalucía Occidental de once tipos de estructuras de fábrica de tapia, que clasifican en tres grupos básicos: monolíticas, encadenadas y mixtas.

Los ejemplos considerados en esta investigación justifican las afirmaciones de los autores sobre el uso en época almohade de los tipos monolítico y encadenado y el predominio de la solución encadenada a partir de la Reconquista.

Mientras los lienzos, por requerir una ejecución más rápida y no estar expuestos a solicitaciones transversales que justifiquen los encadenados de refuerzo, se ejecutan en tapial monolítico, las torres presentan soluciones diversas, tanto las almenara como las de recintos amurallados. Aun siendo la mayoría monolíticas, existen ejemplos de torres encadenadas en piedra nunca en ladrillo; se trata bien de torres singulares - albarranas o vigía - (Torre de San Antonio, Castillo de Almenara, Torre del Oro) o bien (aunque más puntualmente) algunas torres de recintos amurallados (Murallas de Niebla y Reina). En estos casos, se utilizan sillares reaprovechados, romanos o árabes, lo que genera una falta de coincidencia entre los hilos de tapia y las juntas en los tramos de sillería.

La diversa tipología de fábricas en las torres puede deberse a factores diversos: la complejidad de la construcción y la cualificación de la mano de obra (ya que las monolíticas resultan de más fácil ejecución), la disponibilidad de sillares para los encadenados y la calidad y el carácter de la construcción. Así, a diferencia de lo que sucede en Niebla, en las torres de los recintos amurallados de Sevilla, Écija, Carmona, Estepa, Marchena o Jerez de la Frontera, no es frecuente la fábrica encadenada, quizás por bastar la solución monolítica al contar estos recintos con otros recursos defensivos. Cuanto más, dichas torres presentan una o dos verdugadas en el nivel correspondiente al paso de ronda (por ejemplo, en las torres de las murallas de Sevilla y Marchena). La solución monolítica se aprecia también en torres de baja calidad edificatoria; por ejemplo, en algunas de la muralla de Écija (en Calle Merinos, 1 y 2) o en pequeños castillos rurales, como la Hacienda de los Quintos; en estos casos la tapia monolítica puede relacionarse también con la inexistencia de los materiales necesarios y con un menor riesgos de ataque, por no tratarse de áreas fronterizas.

Mientras en las construcciones religiosas y civiles de época cristiana se generaliza la solución encadenada para resolver las solicitaciones transversales, los lienzos militares del momento mantienen la solución monolítica almohade. Por el contrario, las torres cristianas son comúnmente encadenadas. De hecho, lo son casi todas las torres cristianas consideradas en el presente estudio: la de los Herberos, la Torre Homenaje del Castillo de Utrera, la de la fortaleza de Alcantarilla y las de los Castillos de Estepa, Setefilla y la de Los Molares. La torre del Castillo de Hierro constituye la única excepción.

En consecuencia, no cabe aplicar el criterio estructural para adscribir las fábricas de datación incierta a un periodo u otro. A excepción del empleo cristiano de 


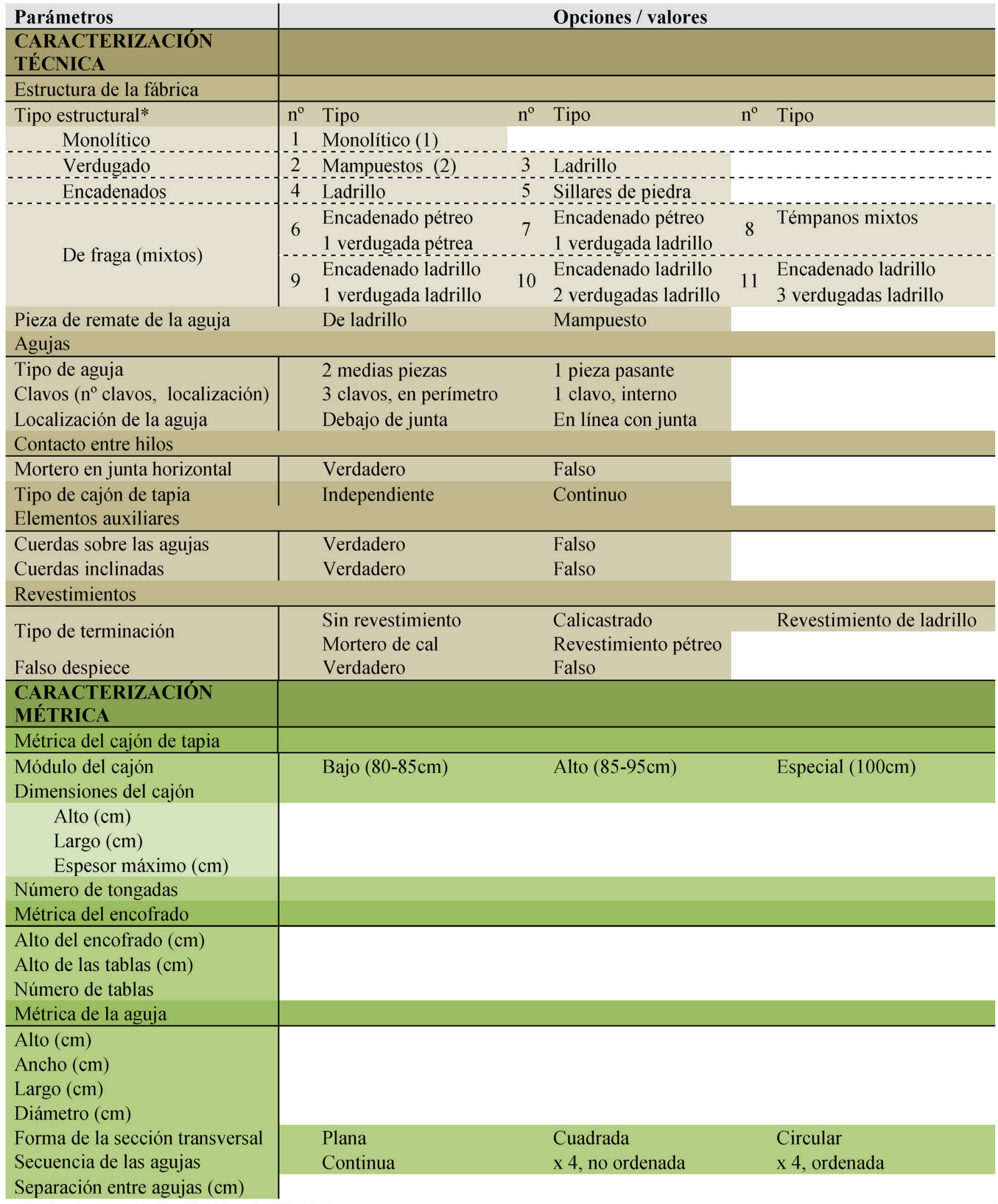

(*) Según Graciani y Tabales 2008: 139

Fig. 5. Clasificación de los parámetros constructivos considerados en el análisis. 
encadenados de ladrillo en torres, el uso de remates latericios sobre las agujas de sección cuadrada (en muchos casos evidenciada por la oquedad del mechinal) puede ser uno de los argumentos para justificar su construcción cristiana. Por lo tanto, esta solución parece propia de fábricas tardías (siglo XIV), y principalmente de muros de espesor reducido; así sucede, por ejemplo, en la Torre de los Herberos y en los lienzos exteriores del Castillo de Luna. Por ello, la presencia de ese recurso en uno de los casos estudiados de datación incierta, en concreto la Torre de la Corchuela (en Dos Hermanas, Sevilla) es uno de los argumentos constructivos que podría contribuir vincular dicha torre al periodo cristiano.

Agujas. Las agujas constituyen un elemento importante de la caracterización. En relación a éstas se consideran tres parámetros de análisis: el tipo, según se usen agujas completas y pasantes (atravesando el espesor del paramento), o bien grupos de dos medias agujas; su posición respecto al tendel inmediato, dado que, aun quedando siempre por debajo de éste la aguja, ésta cuestión evidencia diferentes tipos de actuaciones previas a su colocación; y la disposición de los clavos que las fijan al soporte, según se usen tres perimetrales o uno central.

Respecto al tipo de aguja, en todos los ejemplos almohades considerados, con independencia de la tipología arquitectónica, se usan medias agujas planas; con esta solución, propia de la construcción almohade militar, se consigue solventar el mayor espesor de la fábrica optimizando los medios disponibles. Aun no siendo un recurso específicamente cristiano, a excepción de los lienzos del Castillo de Luna (Barrios, Graciani y Núñez 2012), se han documentado agujas planas en las restantes construcciones cristianas; ello puede justificarse por corresponder a una fase inmediata a la Reconquista, por la pervivencia de mano de obra almohade o, simplemente, por perdurar la tradición constructiva almohade. La utilización de agujas pasantes en la Torre de la Corchuela en Dos Hermanas, cuya adscripción hemos puesto en duda previamente, podría ser otro argumento más para identificarla como una torre cristiana.

Los ejemplos localizados evidencian que en el área geográfica estudiada se disponen tres clavos apoyados sobre el perímetro de una media aguja (Fig. 6), plana y normalmente de $7-8 \mathrm{~cm} \times 2-3 \mathrm{~cm}$, como efectivamente se constata en casi todos los casos registrados. Sin embargo, en otras fortificaciones coetáneas en Andalucía Oriental y el Levante peninsular, se suele emplear un único clavo perforando la testa de la media aguja (Climent, Gandía y Giner 2011: 267; López 1999; Martín 2005).

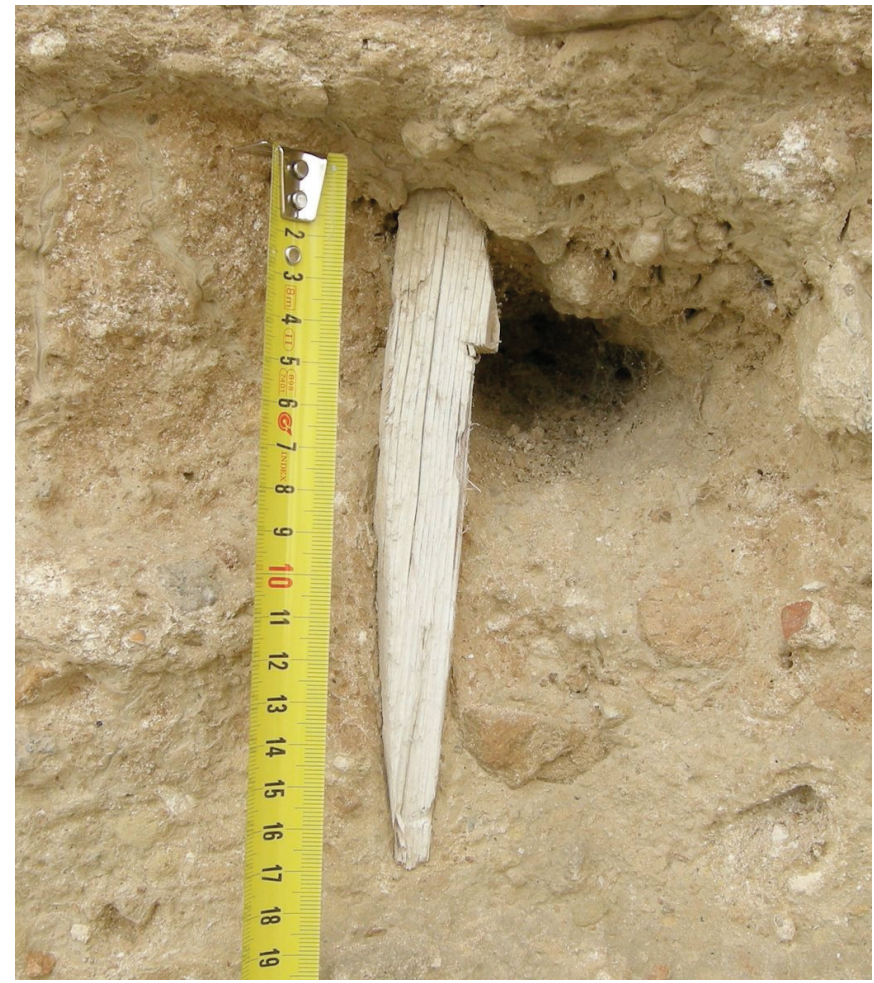

Fig. 6. Clavo embutido en la tapia (Castillo de Sanlúcar la Mayor).

La existencia de restos de clavos o bien de la huella que éstos han dejado ha permitido determinar su uso sólo en siete de los cuarenta y seis casos estudiados, con independencia de vinculación almohade o cristiana de la construcción. En concreto, entre los almohades, el Mirador Almohade de la Muralla de Marchena, las murallas de Sanlúcar la Mayor, San Juan de Aznalfarache y de Sevilla en el tramo de Casa de la Moneda; entre los cristianos, los castillos de Alhonoz y los Molares y entre los de datación incierta el Castillo de Tejada. No obstante, dado que estos seis registros abarcan muchos tipos y morfologías de fábricas, cabe pensar que el uso de este tipo de aguja fue genérico. Salvo en el Castillo de Tejada (en donde sólo se ha podido apreciar un clavo central en la cara de la aguja), en los restantes quedan visibles tres clavos, colocados en el contorno de la aguja, lo que puede indicar que este sería el número habitual para fijar cada media aguja a la argamasa.

Contacto entre hilos. A la vista de los ejemplos analizados, se deduce que en las fábricas almohades el contacto entre los hilos se realizaba de modo directo o bien disponiendo de una capa de mortero, de entre 2 y $4 \mathrm{~cm}$ de espesor, a fin de regularizar el asiento del cajón superior, mejorar los apoyos y la adherencia entre los hilos y absorber los movimientos de los cajones (Graciani y Tabales 2008). Aunque tras la Reconquista, durante los siglos XIII al XV, continúan apreciándose ambas soluciones, la 


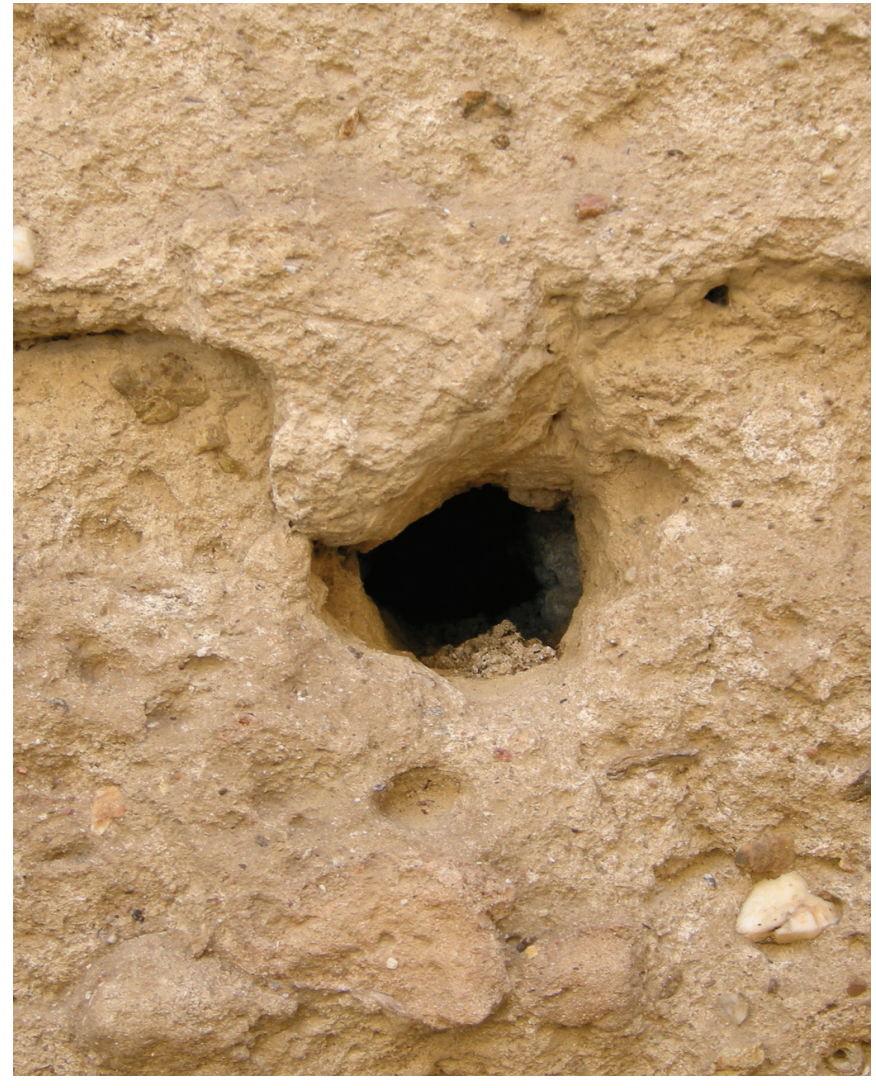

Fig. 7. Mechinal bajo la junta horizontal y cubierto de una capa de mortero de cal (Torre de la Dehesilla, Aznalcázar).

mayor proporción de ejemplos contrastados de fábricas con tongadas de mortero podría responder a su progresiva generalización como una evolución constructiva que además evitaría realizar cajeados previos para colocar las agujas del hilo superior (Fig. 7). En este sentido, las agujas de las fábricas más tardías quedan insertas en la capa de mortero, como se aprecia en el Castillo de Utrera y en la Torre de la Alcantarilla (Fig. 8), y no bajo ella; también se detectan ejemplos de utilización de pequeñas piedras en el contacto entre hilos (Fig. 8).

La posición de la aguja respecto a la junta denota ciertas tendencias, aunque no se pueden asociar a periodos históricos dada la dispersión de datos. En más de la mitad de las fábricas almohades la aguja aparece unos 9 o $10 \mathrm{~cm}$ por debajo de la junta, lo que según algunos autores supondría realizar los cajeados sobre el cajón terminado (López Osorio 2012, Martín 2005, Font e Hidalgo 2009). Sin embargo, en lugar de este proceso, con el fin de evitar desperfectos, estos cajeados se podrían haber conformado al compactar la última tongada colocando unas hormas recuperables donde posteriormente se alojarían las agujas (Font e Hidalgo 2009; Doat, Hays, Houben, Matuk y Vitoux 1991).

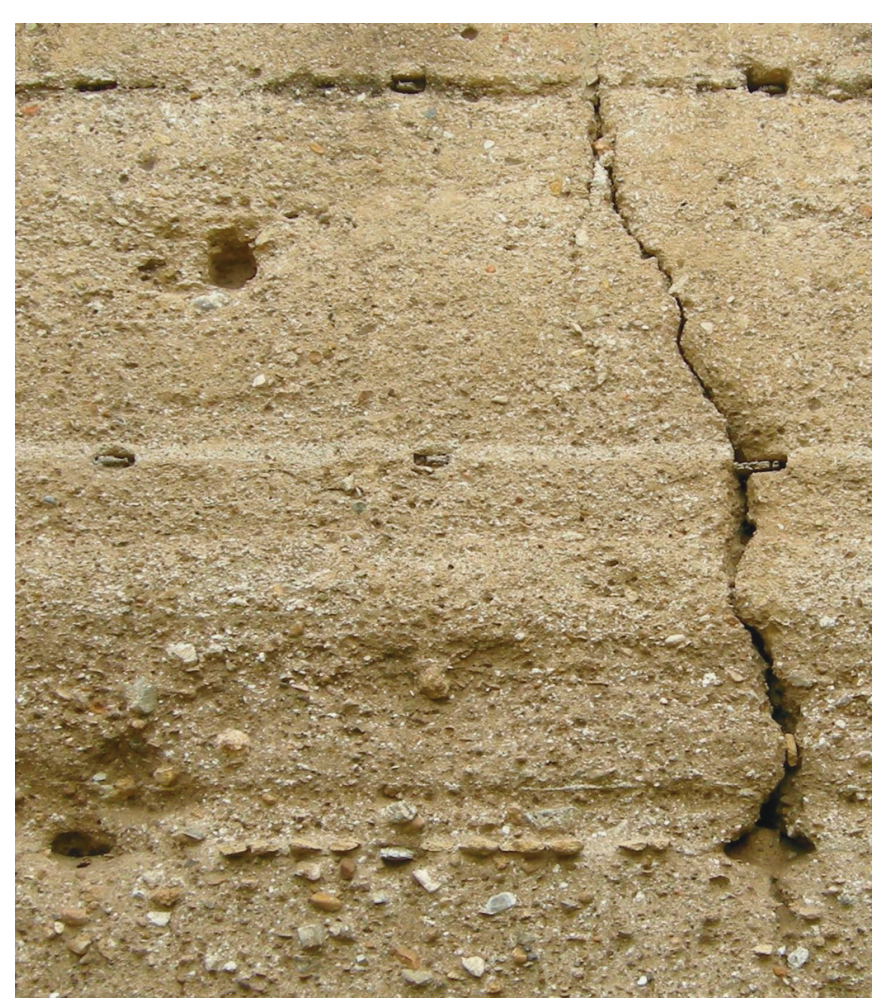

Fig. 8. Mechinal en línea con la junta horizontal con capa de mortero de cal y piedras (Torre de Alcantarilla, Castillo de Utrera).

Asimismo, si no hay tallado, la aguja se coloca encima y se rellena el espacio vacío mediante un mortero y piedras (Font e Hidalgo 2009: 102), agilizando así el proceso de ejecución. Esta colocación desfasada de la aguja (Figs. 6 y 7) deja espacio para una cuerda y un solape entre la tapia inferior y el encofrado para impedir su deslizamiento. Tal disposición de las cuerdas y agujas se ha hallado solo en la muralla de Sevilla, aunque es posible que sea una solución más extendida.

Tipología de cajón. La aparición del cajón continuo o corrido es una novedad almohade que en el ámbito del SO peninsular se vincula a las construcciones de finales del siglo XII y comienzos del XIII (Márquez y Gurriarán 2008: 118; Graciani 2009: 121), pero que también está presente en otros ámbitos geográficos, por ejemplo en el levante peninsular (López 1999: 83; Climent, Gandía y Giner 2011: 266). Este tipo de encofrado mejora el rendimiento de ejecución, al ahorrar tareas y agilizar el proceso, y además facilita el armado, el vertido del material y el apisonado de la argamasa. En consecuencia, la ejecución con encofrados simples es más lenta y laboriosa.

Para analizar la tipología del cajón de encofrado es necesario considerar la organización de las llagas o juntas entre tramos de argamasa. En concreto, una secuencia uniforme de llagas verticales evidenciará que 

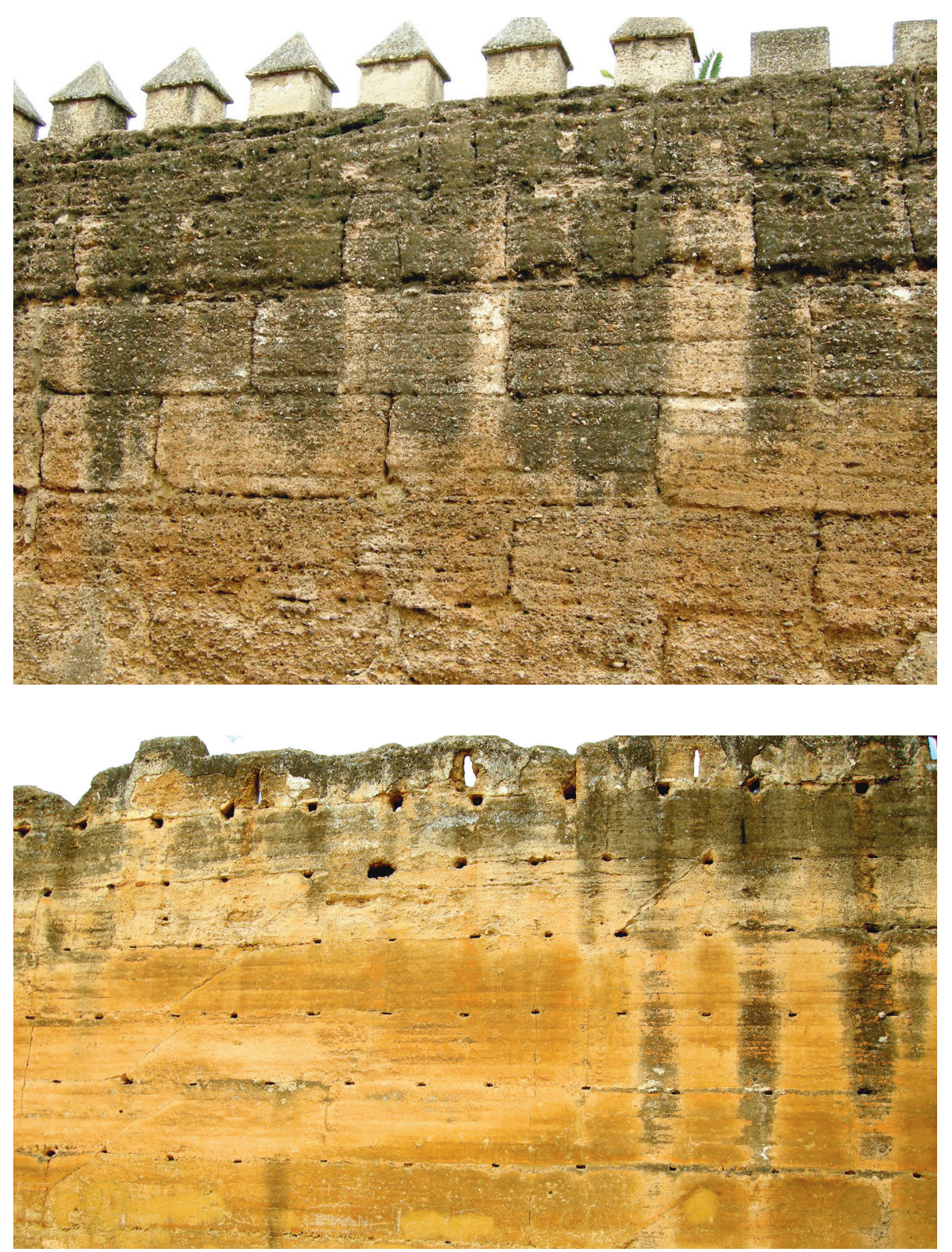

Fig. 9. Lienzo construido mediante cajones independientes, mostrando las juntas verticales (Muralla de Sevilla).
Fig. 10. Lienzo construido con cajones corridos y muestra las típicas juntas inclinadas (Castillo de Alcalá de Guadaíra). la construcción se ha realizado mediante un cajón único de encofrado o con varios de igual módulo (Fig. 9); por el contrario, la presencia de juntas oblicuas y más distanciadas implicará el uso, en un mismo hilo o en parte de éste, de un encofrado continuo, sin fronteras, correspondiendo cada junta al encuentro de dos tramos yuxtapuestos (Fig. 10).

$\mathrm{Su}$ estudio también proporciona información sobre la duración, el sentido y el alcance del proceso constructivo; así, la orientación de la llaga evidencia el sentido de la ejecución y de existir juntas contiguas con diferente inclinación, la participación de dos cuadrillas de obreros, avanzando en sentidos opuestos, probablemente para agilizar la construcción en respuesta a las recurrentes incursiones militares (Graciani y Tabales 2008: 147). Esta solución constructiva evitaría las juntas inclinadas cuando, como, sucede en la Torre del Oro, los encofrados corridos se encastran en los encadenados de ángulo.

Gran parte de los casos almohades considerados $(60 \%, 15 / 24$ casos) se ejecutaron mediante la técnica del cajón continuo. Entre los que hicieron uso de tapiales independientes se encuentran el Castillo de Paderne y la Muralla de Sevilla (en tres fábricas), en cuyos tramos de la Macarena, los Jardines del Valle y el Callejón del Agua se aprecia claramente la independencia de cada cajón; esto no sucede en su correspondiente barbacana ni en los nuevos hilos superiores de la muralla, obras que según algunos autores son posteriores (Jiménez Maqueda 1996), como así 
lo atestiguan las juntas inclinadas. Este avance cualitativo en el proceso de construcción perdurará en la construcción cristiana, constatándose en todos los ejemplos cristianos considerados en el presente estudio. Por su parte, el castillo de Paderne, que Catarino (1997) adscribe al siglo XI, pudiéndose establecer un paralelismo constructivo con las fábricas de cajones independientes de la muralla de Sevilla, las que, como recoge Jiménez Maqueda (1996), según algunos autores podrían ser también de factura anterior a los almohades (Jiménez y Pérez 2012: 275).

Evidencias de medios auxiliares. El registro de los indicios que definen las particularidades de los medios auxiliares (cuerdas, tensores y puntales) empleados en la fijación de encofrados ha sido una base argumental fundamental a la hora de determinar la caracterización constructiva de las fabricas almohades; así, de quedar visibles, se han registrado las huellas de los puntales y las sogas que, bien a lo largo de la cara de la aguja (Martín 2005 y López Osorio 2012) o bien sobre ella y ascendiendo en diagonal hacia la cara opuesta, atan los elementos del encofrado.

Pese a la importancia de esta información, los datos obtenidos en las construcciones evaluadas no son realmente significativos, pues al quedar embutidos en el interior de la fábrica, no siempre resultan visibles. De hecho, sólo se han localizado huellas de cuerdas (de 1 a 1,5 cm de diámetro) sobre las agujas de la barbacana de la Muralla de Sevilla (Fig. 11), que, probablemente, siguiendo un patrón similar al encontrado en la Alcazaba de la Alhambra (Fig. 12), fijaran los costales o el borde

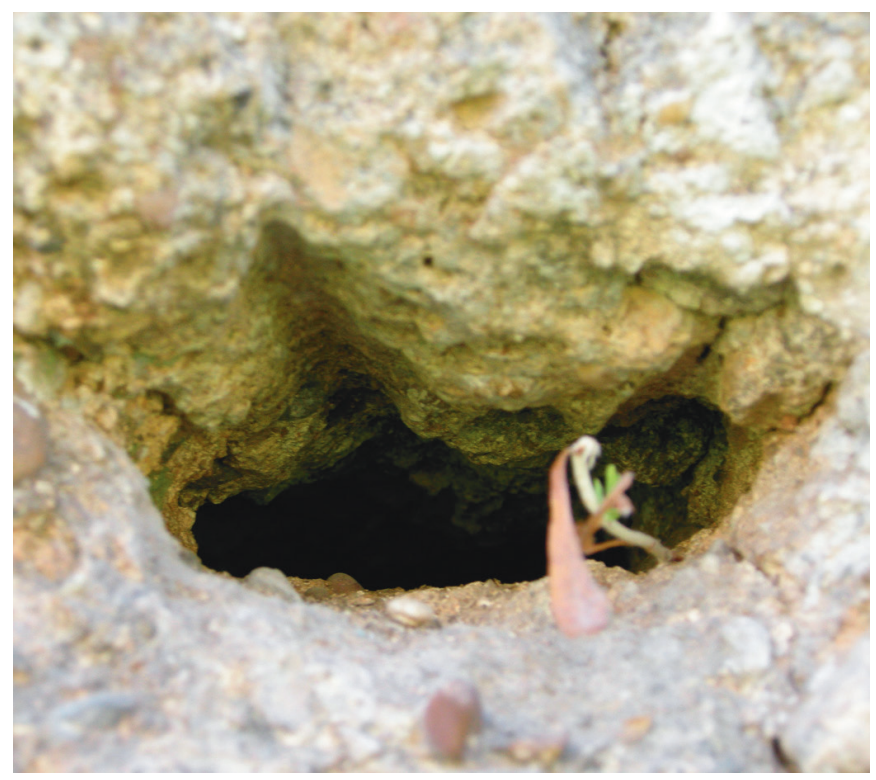

Fig. 11. Marca dejada por una cuerda sobre la aguja (Muralla de Sevilla, tramo de la Macarena).

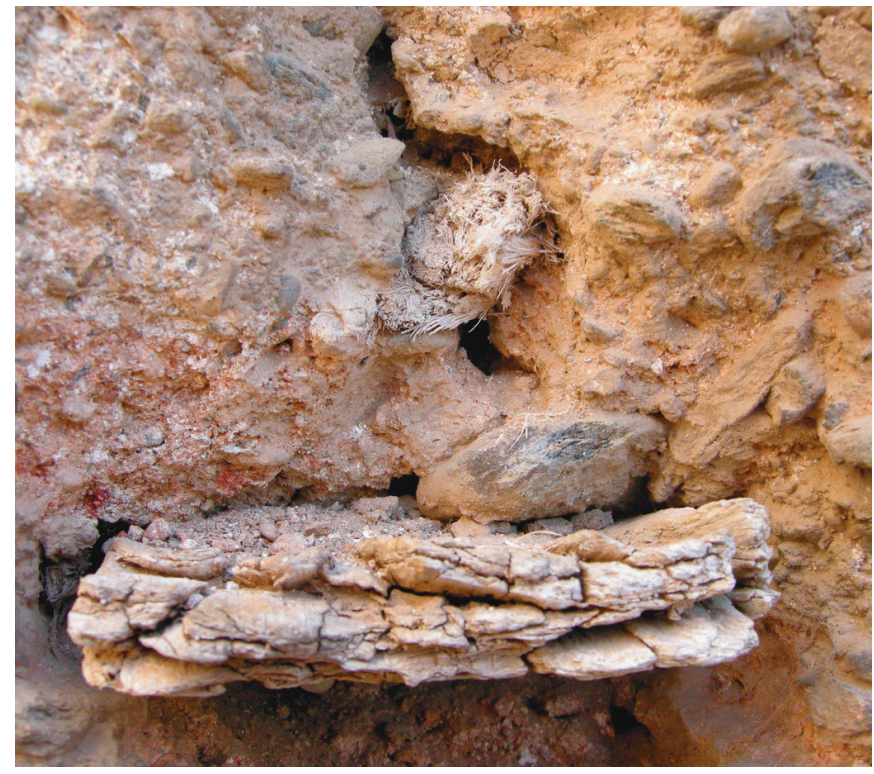

Fig. 12. Cuerda sobre una aguja (Alcazaba de la Alhambra de Granada).

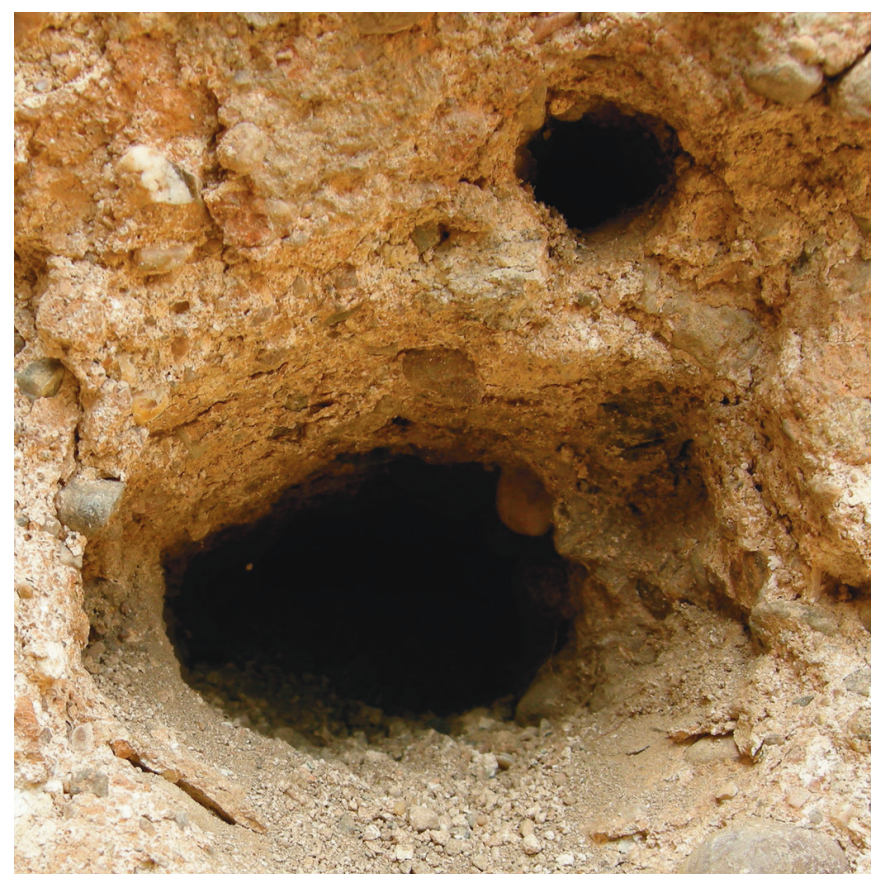

Fig. 13. Marca de una cuerda que asciende sobre el mechinal (Muralla de Sevilla, tramo de la Macarena).

inferior del encofrado (López Osorio 2012); esta disposición se asocia más a la colocación de la aguja con mayor desfase bajo la junta horizontal y que además aporta la mayor holgura que se necesita para introducir la cuerda.

No obstante, en la Muralla de Sevilla, en el lienzo principal de la Macarena, en Paderne y en la Muralla de Marchena, las cuerdas se disponen de modo diferente; en ellas, una o dos ascienden en diagonal hacia la cara opuesta (Fig. 13), posiblemente para atirantar el sistema 


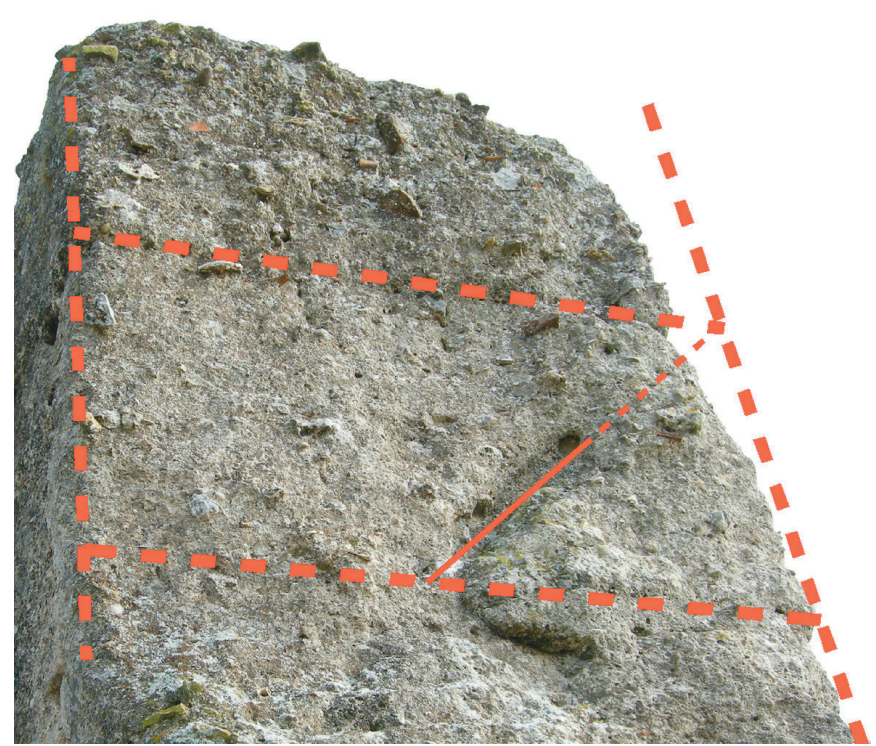

Fig. 14. Huellas de un puntal en el interior de un cajón (Castillo de Alhonoz).

mediante retorcimiento, como efectivamente se realiza en la tapia tradicional (Doat, Hays, Houben, Matuk y Vitoux 1991; Cuchí 1996). Esta solución se relaciona más estrechamente con la disposición de la aguja en línea, y al contrario que la disposición anterior, quedaría menos espacio para introducir la cuerda.

En los casos almohades analizados se han encontrado muy pocas huellas de los puntales que, cuando la horma estuviera vacía, se colocarían en el interior de los cajones a fin de resistir el vuelco del encofrado hacia dentro. Tales puntales, de mayor diámetro $(4-5 \mathrm{~cm})$, serían eliminados o cortados una vez que el cajón hubiera sido parcialmente colmado, por ser innecesarios y para facilitar la compactación (Fig. 14). Tan sólo se han localizado en una torre del Castillo de Lora del Río y, ya de época cristiana, en la torre del Homenaje del Castillo de los Molares y en un lienzo del Castillo de Alhonoz (Écija); en cualquier caso, las huellas no corresponden a toda la longitud del puntal por el modo en que éste se usa y se desmonta.

Aunque no se ha registrado el empleo simultáneo de tensores y puntales, el reducido número de casos y su compleja localización evita descartar que fueran recursos compatibles y combinables entre sí.

Revestimientos. Un importante número de las fábricas de tapia registradas (25 casos) aparecen desprovistas de revestimiento (el 50\% casos almohades constatados y el $40 \%$ de los cristianos); en estos casos, es la propia dureza de la tierra y la cal lo que les confieren la protección superficial.

Sólo uno de los veinticuatro casos almohades estudiados evidencia claramente el calicostrado. Hay que tener en cuenta que el calicostrado, que se realiza durante el proceso de ejecución del cajón de tapia, apenas está presente en las fábricas árabes de los siglos XII y XIII, pues fue especialmente en época nazarí (siglo XIV), cuando el empleo de cal se hizo más eficiente y el calicostrado se hizo más común. En cualquier caso, los calicostrados de factura árabe aparecen generalmente en los hilos superiores y los merlones de las fábricas, a fin de generar una barrera impermeable al agua y facilitar la correcta transpiración del exceso de vapor de agua (Márquez y Gurriarán 2008: 119).

Entre los ejemplos cristianos estudiados, la proporción de casos localizados (cuatro de diez) ha sido mayor; así han apareciendo en la Torre de los Herberos, el Castillo de Luna, el de Alcalá de Guadaira, y la Torre de Alcantarilla. Con ello, se confirma la hipótesis de autores previos que corroboraron que esta solución es más propia de las fábricas más tardías, mientras que en las más tempranas era el hormigón de cal lo que confería a la fábrica su resistencia superficial (Valverde, Ontiveros y Sebastián 1997; Martín 2005; López Osorio 2012).

En referencia a otro tipo de terminaciones, cinco de las cuarenta y seis construcciones analizadas presentan falsos despieces, un tipo de revestimiento ya extendido en época almohade (Climent, Gandía y Giner 2011) incluso con inscripciones propagandísticas del Estado (Márquez y Gurriarán 2008); en concreto, aparecen en el Castillo de Paderne, en la Muralla de Niebla y, ya de época cristiana, en el Castillo de Luna; también se ha localizado en otras dos construcciones de adscripción incierta (la Torre de Corchuela y el Castillo de Hornachos). En cualquier caso, se trata de restos muy aislados y deteriorados; además, por no estar localizados en los lienzos estudiados, pese a su importancia, no han podido ser incluidos en el análisis constructivo.

Por último, algunas fortificaciones presentan además forros o parcheados de ladrillo o mampostería, añadidos como resultado de reparaciones posteriores no almohades.

\section{Caracterización métrica}

Las medidas de los cajones, de sus agujas y de los mechinales de los casos objeto de este estudio han sido registradas con objeto de interpretar los datos sólo en un modo amplio, entendiendo que éstas pueden experimentar oscilaciones y aceptando que sería la altura de los tableros lo que marcaría el módulo y no la altura del tramo encofrado (Graciani y Tabales 2008).

Cajones y encofrados. En concreto, se ha medido el ancho de los cajones, que corresponde al espesor del 
muro; el largo, cuando aparecen juntas verticales de construcción, y el alto, que se referencia según los módulos bajo $(80-85 \mathrm{~cm})$ y alto $(90-95 \mathrm{~cm})$ propuestos por Graciani y Tabales (2008).

El predominio de los cajones que Graciani y Tabales (2008) ha denominado de módulos altos (de $85 \mathrm{~cm}$ a $95 \mathrm{~cm}$ ) se confirma en las fábricas almohades analizadas, entre las cuales sólo presentan alturas menores a $85 \mathrm{~cm}$ los tapiales del Castillo de Guillena $(75 \mathrm{~cm})$, las Murallas de Niebla y la Torre de San Antonio $(80 \mathrm{~cm})$. Las mediciones efectuadas confirman la consolidación del módulo alto en época cristiana. Sin embargo, en muchos de los casos considerados de datación incierta el módulo predominante es bajo (presentando $80 \mathrm{~cm}$ de altura los tapiales de la Torre de la Dehesilla, el Castillo de las Guardas, la Hacienda de Quintos y el Castillo de Hornachos); en cualquier caso, el módulo de estos ejemplos no es argumento suficiente para adscribirlos a las fases previas y tempranas almohades, porque la altura de los cajones podría depender de procedimientos constructivos locales y de circunstancias específicas de cada obra (Márquez y Gurriarán 2008).

La longitud del cajón (cuando no se aplican cajones corridos sino un tapial común) abarca de $2,1 \mathrm{~m}$ a 2,5 m. Para determinarlo, se valoran solo las distancias entre juntas verticales pero sin confundirlas con las marcas verticales consecutivas de dos encofrados, que no son juntas estructurales.

El espesor del muro, pudiendo ser múltiplo del codo mamuní $(47,14 \mathrm{~cm})$, es variable y abarca desde 1,15 $\mathrm{m}$ hasta casi $3 \mathrm{~m}$. Normalmente, en las torres árabes o cristianas se emplean espesores menores, entre $1 \mathrm{~m} \mathrm{y}$ 1,5 m (2-3 codos mamunies) dependiendo de la planta, ya que su configuración estructural es más estable que un lienzo. No obstante, ciertas torres cristianas de gran envergadura (Torres del Homenaje en Estepa y Utrera) alcanzan de 2 m a 2,5 m (4-5 codos mamunies). Asimismo, los lienzos suelen mantener la sección constante, mientras que las torres disminuyen en altura, por lo que se toma el espesor máximo, que es el de la base, que además es la sección que siempre se conserva mejor en cualquier torre. Por otro lado, los lienzos, independientemente de su origen, siempre se construyen con mayores espesores, de entre $1,8 \mathrm{~m}$ a $2,5 \mathrm{~m}$, que según la figura 15, corresponden aproximadamente a 4 codos mamunies; de ser necesario su refuerzo, por ejemplo ante una previsible crecida fluvial, se aumentaría hasta 5 o 6 codos, como sucede en los lienzos de Niebla y en el tramo de la muralla de Sevilla en la Casa de la Moneda.

En ocasiones las huellas dejadas en la masa del cajón por las tablas de madera resinosa (Gurriarán y Daza 2002: 570) que lo conforman, permiten conocer el número de éstas. Las tablas se separarían unos milímetros entre sí (Cuchí 1996) a fin de expulsar el agua sobrante del amasado de la mezcla; en una cara, las unirían dos barzones (López Osorio 2012), en vez de una por cara del tablero como se hacía en Levante (Soler 2009), empleándose ocho clavos de hierro de cabeza redonda, en ocasiones marcadas en el paramento Fig. 16).

En concreto, en las edificaciones estudiadas, se han encontrado marcas en construcciones almohades (Hacienda de los Quintos, Castillo de Lora del Río y Muralla de San Juan de Aznalfarache y Paderne), en cristianas (Castillos de Estepa, Setefilla, Luna y Utrera) y en el Castillo de Alcalá, de datación indeterminada. A excepción del Castillo de Utrera donde se emplearon

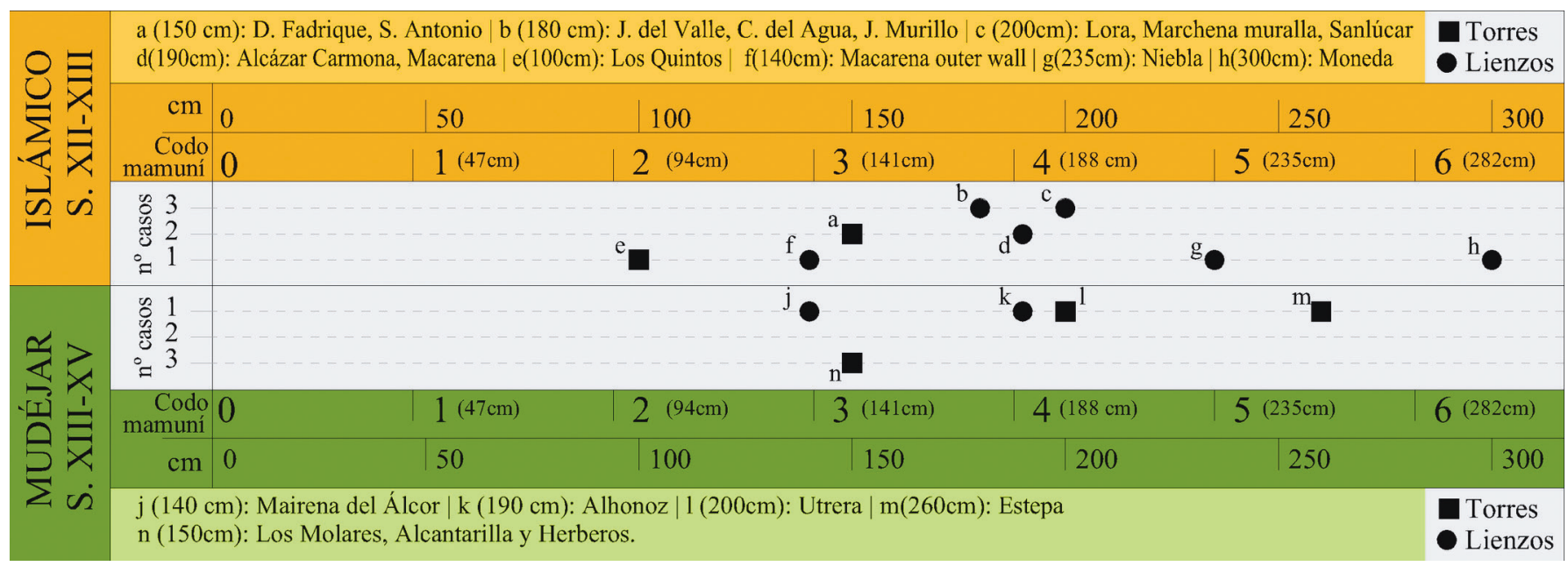

Fig. 15. Representación gráfica del registro de espesores máximos en relación al codo mamuní. 


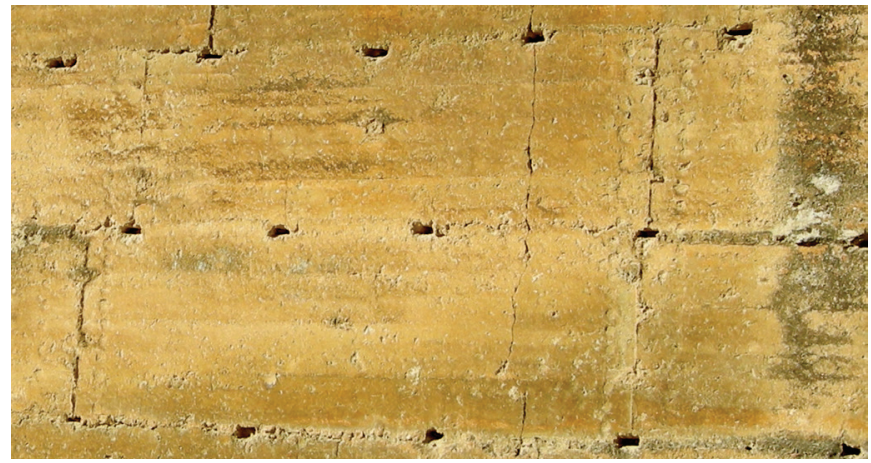

Fig. 16. Huellas de los encofrados sobre el lienzo (Castillo de Alcalá de Guadaíra).

tres tablas (como en la Muralla del Albaicín), en los restantes casos documentados, aparecen cuatro tablas (correspondientes a 2 codos mamunies).

Aunque el alto del encofrado no se puede determinar, debe ser algo mayor al del cajón, por lo que debería superar los $90 \mathrm{~cm}$, encajado así con un encofrado de 2 codos mamuníes $(94 \mathrm{~cm})$, tanto para los módulos bajos $(80 \mathrm{~cm})$, como para los altos $(90 \mathrm{~cm})$. Las tablas de los tableros del encofrado tendrían aproximadamente $20 \mathrm{~cm}$ de altura.

Debido a la erosión superficial de muchas tapia, el largo del encofrado solo ha sido registrado en el caso del Castillo de Alcalá de Guadaira, correspondiendo a 2,5 $\mathrm{m}$. Con todo ello, las dimensiones hipotéticas ${ }^{1}$ para estos encofrados serían $2,5 \mathrm{~m} \times 0,95 \mathrm{~m}$ x $0,025 \mathrm{~m}$, cuyo peso sería el máximo ${ }^{2}$ que uno o dos operarios podrían manipular con agilidad (Cuchí 1996). Además coincide con los encofrados tradicionales actuales y con algunas observaciones sobre otras fábricas en el Reino de Granada (López Osorio 2012) y del Levante Peninsular (Font e Hidalgo 2009; Climent 2011: 227). Todas estas evidencias se han hallado tanto en fábricas almohades, cristianas, como en otras de datación incierta, lo que parece indicar una cierta continuidad constructiva.

Como en la tapia doméstica, también es posible encontrar muescas practicadas en los extremos y en medio del encofrado empleadas para facilitar su manipulación (Fig. 17).

Número de tongadas. De quedar evidencias, se ha registrado el número de tongadas por cajón, a fin de

\footnotetext{
El espesor del encofrado no es conocido, pero de la observación de los actuales y de la capacidad máxima de carga de un obrero, se puede suponer que no sobrepasarían los $3 \mathrm{~cm}$, como así afirman J. Rondelet y J. de Villanueva en sus tratados Traitéthéorique et pratique de l'art de bâtir y Arte de albañilería, respectivamente.

2 Suponiendo una densidad de $460 \mathrm{~kg} / \mathrm{m}^{3}$ para una madera de pino y el volumen de un encofrado estándar $(250 \mathrm{~cm}$ x $95 \mathrm{~cm}$ x 2,5 cm), el peso ascendería a unos $27 \mathrm{~kg}$.
}

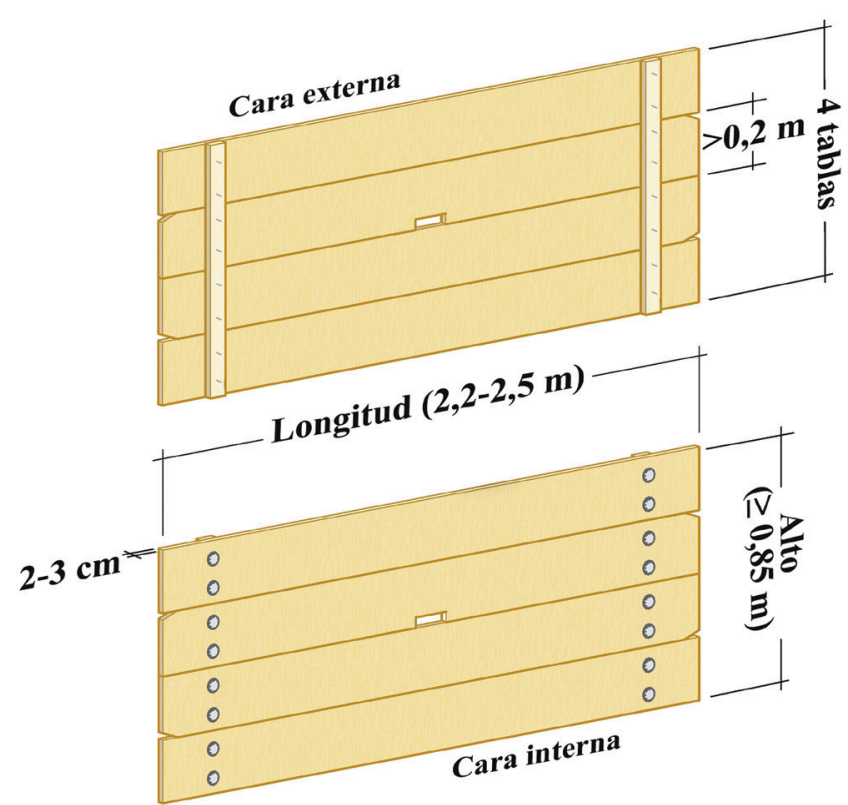

Fig. 17. Propuesta métrica y formal de encofrado tipo empleado en fortificaciones.

argumentar la calidad de la fábrica; de hecho, ésta mejora, con una mayor compactación cuando las tongadas disminuyen de espesor y aumenta su número. El análisis de casos confirma las afirmaciones de autores como Doat, Hays, Houben, Matuk y Vitoux (1991), quienes indican que en cajones de aproximadamente $90 \mathrm{~cm}$ de altura, se compactarían (manualmente) 10 u 11 tongadas. Así, a excepción de la Torre del Homenaje del Castillo de Estepa (donde se han registrado 9 tongadas para unos $90 \mathrm{~cm}$ del cajón), los casos analizados muestran de 10 a 12 tongadas, por lo que, considerando un módulo medio de $0,9 \mathrm{~cm}$, se obtiene un espesor medio de tongada de $9-10 \mathrm{~cm}$. Por ello, con independencia de la cronología, todas las fábricas parecen haber seguido unos criterios generales muy similares, heredados de la tradición de los maestros alarifes árabes.

Agujas. En el estudio realizado se han considerado tres cuestiones relacionadas con las agujas del encofrado o tapial, sin duda, uno de los elementos más representativos de este tipo de fábricas. Asimismo, además de la tipología de las agujas (según su sección, plana, cuadrada o circular) y sus medidas, en caso de quedar éstas expuestas, se constató su longitud para poder realizar una aproximación sobre el largo total de la aguja antes del descabezado; como tercera cuestión, se registró el ritmo y la distancia de separación entre las agujas del encofrado, aspecto que, relacionado con la forma de ejecución de los cajones, puede responder a un ritmo uniforme o continuo o bien en secuencias repetidas, normalmente de 4 agujas. 
Las agujas que quedan visibles de todas las fábricas almohades (17 de 24) presentan secciones planas, de aproximadamente 7 a $8 \mathrm{~cm}$ de largo y de 2 a $3 \mathrm{~cm}$ de alto. No es posible conocer su longitud total, por ser descabezadas, si bien considerando que los restos encontrados almohades y cristianos miden $50-60 \mathrm{~cm}$ y considerando unos 10-15 cm para el apoyo de los tapiales, estimamos que el largo total oscilaría entre 60 y $75 \mathrm{~cm}$. La aguja plana suponía un ahorro de material, facilitaba el acoplamiento y nivelación del encofrado y además permitiría perforar su tabla para recibir un costal. La pequeña sección resistente de estas agujas y su sistema de fijación mediante clavos limitaría su capacidad portante a flexión, por lo que descartamos su empleo como soporte de un andamio o elemento auxiliar; solo las agujas de cuadradas de mayor sección $(7-10 \mathrm{~cm}$ x 7-10 cm) encontradas en fábricas cristianas (Castillo de Luna y la Torre de los Herberos) podrían cumplir dicha función. Si bien la aguja plana se empleó entre los siglos XII al XV, la sección cuadrada es exclusiva del ámbito cristiano, siendo de secciones más resistentes y pudiendo ser agujas pasantes y recuperables cuando el espesor es igual o menor a 3 codos, como es el caso del Castillo de Luna.

La separación entre agujas es otra cuestión interesante. Un encofrado de 2,2 a 2,5 m de longitud solía apoyar sobre cuatro agujas, con una separación variable entre ellas, que oscila entre 70 y $80 \mathrm{~cm}$ aproximadamente; a este intervalo se adscribe el $46 \%$ de los veinticuatro casos almohades en que este dato se ha registrado. Se aprecian tres soluciones con relación a la colocación de las agujas; primero un sistema por el que las agujas se distribuyen casi uniformemente (Fig. 18a), otra asociada a las agrupaciones de cuatro agujas (Fig. 18b) y por último, la que emplea una secuencia uniforme y ordenada (Fig. 18c). En las fábricas analizadas con secuencias de grupos de cuatro agujas, las separaciones se adaptan para acoger distintas dimensiones de encofrados, como se ha constatado en otros ámbitos geográficos (Soler 2009).

La primera secuencia es más abundante $(67 \%$ de los casos árabes) y podría implicar el montaje de un encofrado corrido no modular, pues las separaciones de las agujas son muy variables, no se han encontrado marcas en los paramentos de módulos de encofrado y cada hilo mantiene un ritmo totalmente aleatorio. Para la segunda opción (Fig. 18b) las agujas forman grupos de cuatro, coincidiendo cada uno con el largo de un encofrado (aproximadamente 220-250 cm). Parece ser un sistema más modulado y una planificación más medida, pues el
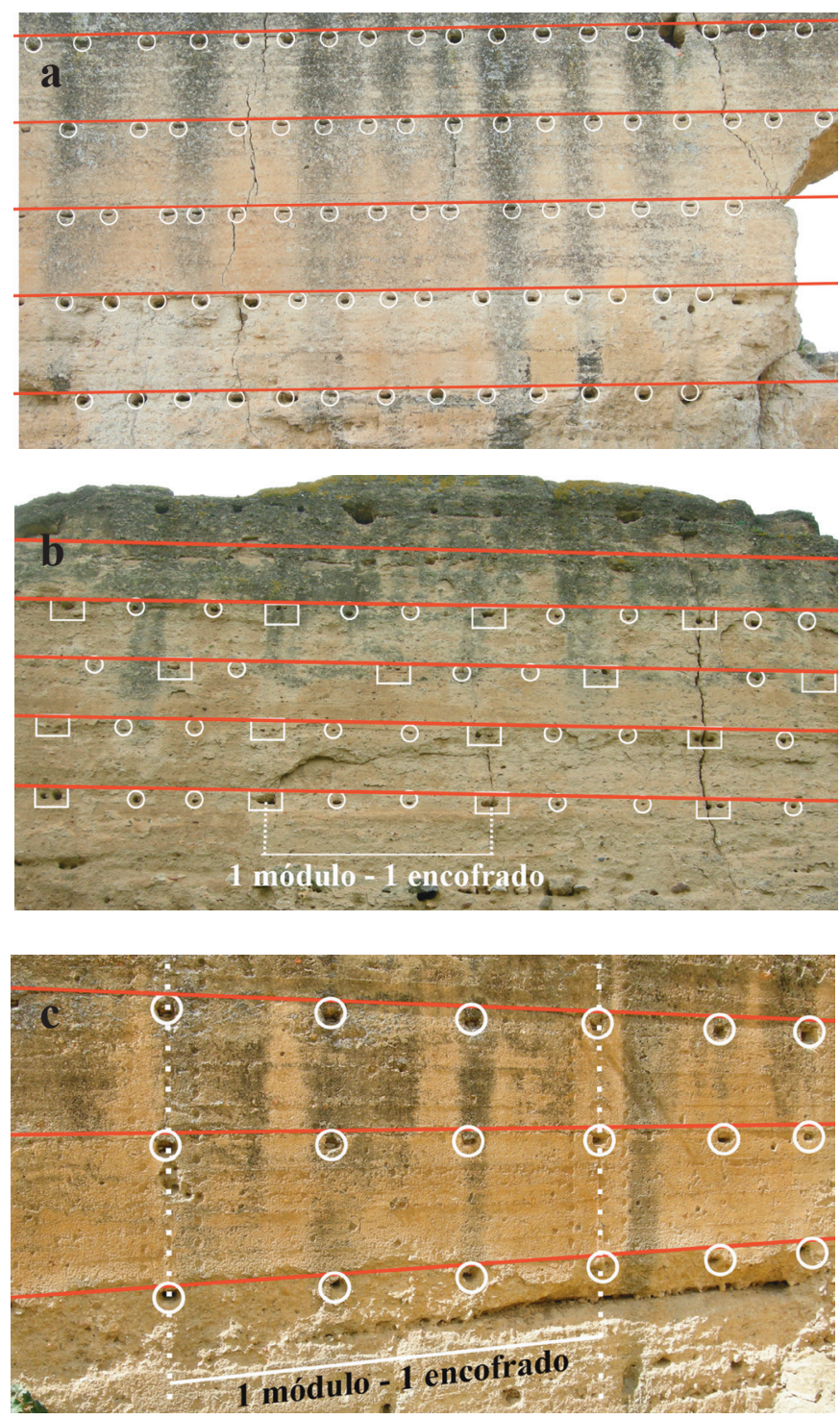

Figs. 18a, 18b y 18c. Representación de los tres tipos de secuencias de agujas. Secuencia uniforme (arriba), secuencia $x 4$ no ordenada (medio) y secuencia $\mathrm{x} 4$ ordenada (abajo).

encofrado siempre apoyaría sobre 4 agujas, a tenor de las marcas entre dos encofrados consecutivos justo en las agujas de los extremos. El último sistema (Fig. 18c) implica la colocación de las agujas en un orden y separación predefinidos y coincidentes entre todos los hilos, por el que cada cuatro agujas definen la longitud de un encofrado, lo que denota una ejecución aún mejor planificada. A diferencia del segundo tipo, la unión entre dos encofrados consecutivos apoya sobre una aguja en lugar de dos, para lo que la aguja plana es más apropiada. A tenor de los resultados, ninguna de estas particularidades puede asignarse claramente a un periodo histórico, salvo el tercer sistema, encontrado en la ampliación del 
Castillo de Alcalá de Guadaíra, que podría pertenecer a un periodo más tardío.

También se han hallado secuencias más concentradas de agujas (entre 0,35 y $0,45 \mathrm{~m}$ ) por lo que si suponemos que a cada aguja se asocia a un grupo de costal, codal y tensor, se delimitan espacios más reducidos de trabajo para el tapiador. Este empleo no es exclusivo de ningún periodo, pues se encuentra en tapias islámicas y cristianas. Se trata, por ello, de una solución funcional, como así también sostienen Font e Hidalgo (2009: 104). Probablemente se emplearan para sostener encofrados más pesados, levantar muros más anchos (Castillo de Alhonoz, 1,9 m de espesor), o como un mero hábito constructivo. La mayor parte de las secuencias cortas se dan en torres (Torres de la Muralla de Écija, Torre de los Quintos o Torre Mocha de D. Fadrique), posiblemente debido a los mayores empujes internos, por ser elementos normalmente macizos. Al doblar el número de agujas y costales, se pueden colocar más tensores frente a los empujes de la compactación un gran volumen. Sirva como ejemplo la Torre del Castillo de Estepa, de origen cristiano, con un volumen de $26 \mathrm{~m} \times 13 \mathrm{~m} \mathrm{x} 13 \mathrm{~m}$ y muros de casi $3 \mathrm{~m}$, donde las agujas las agujas se separan 0,4-0,45 m. Las torres almohades de la Muralla de Écija, vuelven a presentar una separación similar, siendo también de gran envergadura. Sin embargo, la torre de la Hacienda de los Quintos, de menor volumen (14 $\mathrm{m} \mathrm{x}$ $7 \mathrm{~m} \times 7 \mathrm{~m})$ y muros más esbeltos $(1 \mathrm{~m})$, presenta 0,35 $m$ de separación en su tramo inferior; unos encofrados más pesados podrían haber obligado a emplear menor separación, en comparación con su tramo superior (separación de $0,75 \mathrm{~m}$ ). El Castillo de Alhonoz, de origen cristiano y lienzos de $2 \mathrm{~m}$ de espesor, también presenta agujas más concentradas $(0,45 \mathrm{~m})$. Esta fortaleza fronteriza (de la banda morisca) pudo requerir tapias más resistentes, lo que requerirían una compactación más enérgica y un encofrado mejor arriostrado. Por lo tanto, la separación de agujas no marca la evolución temporal del sistema constructivo, pero evidencia rasgos técnicos que definen las distintas maneras de ejecución en respuesta a requerimientos técnicos diferentes.

\section{CONCLUSIONES}

Pese a la carencia o falta de disponibilidad de fuentes más fiables para la datación, ha sido posible acometer un análisis de los parámetros constructivos de las fábricas de tapia militares entre los siglos XII y XV del que se pueden extraer ciertas pautas. Una vez más, se pone en evidencia la importancia de los estudios estratigráficos y documentales como herramientas indispensables en la fase previa a la intervención y posteriormente como apoyo y fundamento de posteriores estudios científicos.

Para describir adecuadamente una fábrica militar de tapia dentro del ámbito espacio-temporal de estudio es necesario atender a todos los rasgos técnicos y métricos propuestos. Sin embargo, también es importante considerar a las circunstancias exógenas del edificio para entender el sentido completo de la técnica constructiva empleada. Por ejemplo, la localización administrativa (urbana o rural) en relación al periodo histórico (como frontera norte almohade hasta 1212, frontera sur cristiana partir del 1248 o no fronterizo) que, como se ha expuesto, condicionan el tipo y calidad de las fábricas. Todos estos parámetros deberían estar presentes en cualquier estudio previo de caracterización, pues serán las bases para establecer criterios sólidos en la intervención patrimonial.

Asimismo, el análisis de los parámetros constructivos considerados puede establecer ciertos criterios de apoyo a la adscripción cronológica de una fábrica de tapia militar. Sin embargo, por la baja especialización que en comparación con otras técnicas (por ejemplo la sillería) la tapia exige, sus procedimientos y pautas tienden a ser flexibles, lo que a su vez dificulta obtener patrones constructivos más o menos constantes. Por ello, no es posible establecer siempre una correspondencia unívoca entre todos los rasgos constructivos estudiados y un periodo histórico concreto. No obstante, es posible categorizar los parámetros constructivos según estén asociados en mayor o menor medida a los dos periodos analizados:

Los parámetros comunes (Fig. 19), es decir aquellos que presentan valores cualitativos o cuantitativos muy similares para cualquier periodo o elemento constructivo (torre o lienzo), denotan cierta continuidad histórica en los métodos de ejecución de las tapias, puesto que la población permanece y los reinos cristianos mantienen, al menos durante los s. XIII al XV, las estructuras administrativas y sociales, por lo que la mano de obra y los procedimientos deberían similares.

Los parámetros característicos (Fig. 20) no son constantes pero muestran diferentes tendencias que permiten establecer relaciones para determinar agrupaciones o tipos genéricos en función del periodo histórico (almohade o cristiano) o del elemento constructivo (torre o lienzo). 


\begin{tabular}{|c|c|c|c|c|}
\hline \multirow{4}{*}{$\frac{\circlearrowright}{\frac{Z}{3}}$} & Agujas & Clavos ( $n^{0}$, localización) & 3 clavos, en perímetros & \\
\hline & Tipo de cajón & Tipo de cajón de tapia & Continuo & \\
\hline & \multirow{2}{*}{ Revestimiento } & Tipo de revestimiento & Sin revestimiento & \\
\hline & & Falso despiece & Verdadero & \\
\hline \multirow{5}{*}{ 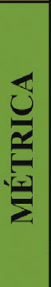 } & \multirow{3}{*}{ Del cajón } & \multirow{2}{*}{ Espesor medio del cajón } & 4 codos & 5 o 6 codos cuando se necesita refuerzo \\
\hline & & & 3 codos & $\begin{array}{l}\text { Algunas torres cristianas muestran } \\
\text { espesores de hasta } 6 \text { codos }\end{array}$ \\
\hline & & Número de tongadas por cajón & 10-11 tongadas & \\
\hline & Del encofrado & Alto del encofrado & $95 \mathrm{~cm}$ & $\begin{array}{l}\text { Correspondería aproximadamente a } 2 \text { codos } \\
\text { mamuníes }(47 \mathrm{~cm})\end{array}$ \\
\hline & De la aguja & Largo de la aguja & $45-60 \mathrm{~cm}$ & \\
\hline
\end{tabular}

Fig. 19. Rasgos comunes para las fábricas de tapia en el Antiguo Reino de Sevilla (s. XII-XV).

\begin{tabular}{|c|c|c|c|c|c|c|c|}
\hline & \multirow{2}{*}{$\begin{array}{l}\text { Periodo } \\
\text { Elemento }\end{array}$} & \multicolumn{2}{|c|}{$\begin{array}{c}\text { Islámico } \\
\text { S. XII-XIII }\end{array}$} & \multicolumn{3}{|c|}{$\begin{array}{c}\text { Mudéjar } \\
\text { S. XIII-XV }\end{array}$} \\
\hline & & & Lienzo & Torre & & & Torre \\
\hline \multirow{4}{*}{ 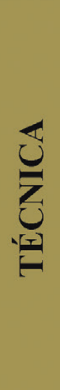 } & \multirow{2}{*}{ Estructura } & $\begin{array}{l}\text { Tipo } \\
\text { estructural }\end{array}$ & Monolítico (1) & $\begin{array}{l}\text { Monolítico (1) } \\
\text { Verdugado (3) }\end{array}$ & \multicolumn{2}{|c|}{ Monolítico (1) } & $\begin{array}{l}\text { Monolítico (1) } \\
\text { Encadenado (5) }\end{array}$ \\
\hline & & Remate de la & No & No & De ladrillo & No & No \\
\hline & Agujas & Tipo de aguja & 2 piezas & 2 piezas & 1 pieza & 2 piezas & 2 piezas \\
\hline & $\begin{array}{l}\text { Contacto } \\
\text { entre hilos }\end{array}$ & $\begin{array}{l}\text { Mortero en } \\
\text { junta } \\
\text { horizontal }\end{array}$ & No & No & No & No & Yes \\
\hline \multirow{4}{*}{$\frac{\underline{u}}{\underline{\underline{v}}}$} & Del cajón & $\begin{array}{l}\text { Modulo del } \\
\text { cajón }\end{array}$ & $\begin{array}{c}\text { Alto } \\
(85-95 \mathrm{~cm}) \\
\text { Bajo } \\
(\mathbf{8 0 - 8 5} \mathbf{~ c m})\end{array}$ & $\begin{array}{c}\text { Alto } \\
(85-95 \mathrm{~cm}) \\
\text { Bajo } \\
(\mathbf{8 0 - 8 5} \mathbf{c m})\end{array}$ & $\begin{array}{c}\text { Alto } \\
(85-95 \mathrm{~cm})\end{array}$ & $\begin{array}{c}\text { Alto } \\
(85-95 \mathrm{~cm})\end{array}$ & $\begin{array}{c}\text { Alto } \\
(85-95 \mathrm{~cm})\end{array}$ \\
\hline & \multirow{3}{*}{ De la aguja } & $\begin{array}{l}\text { Sección } \\
\text { de aguja } \\
\text { (alto x ancho) }\end{array}$ & $\begin{array}{c}\text { Plana } \\
(7 \times 3 \mathrm{~cm})\end{array}$ & $\begin{array}{c}\text { Plana } \\
(7 \times 3 \mathrm{~cm})\end{array}$ & Cuadrada & $\begin{array}{c}\text { Plana } \\
(7 \times 3 \mathrm{~cm})\end{array}$ & $\begin{array}{l}\text { Cuadrada } \\
\text { Plana } \\
(7 \times 3 \mathrm{~cm})\end{array}$ \\
\hline & & $\begin{array}{l}\text { Secuencia de } \\
\text { las agujas }\end{array}$ & $\begin{array}{c}\text { Continuo } \\
\times 4 \text { no ordenado }\end{array}$ & Continuo & $\begin{array}{c}\text { Continuo } \\
\mathbf{x} 4 \text { ordenado }\end{array}$ & $\begin{array}{c}\text { Continuo } \\
\mathbf{x} 4 \text { ordenado }\end{array}$ & Continuo \\
\hline & & $\begin{array}{l}\text { Separación de } \\
\text { agujas } \\
(\mathrm{cm})\end{array}$ & $70-80$ & $\begin{array}{l}70-80 \\
\mathbf{3 5 - 4 5}\end{array}$ & & $70-80(*)$ & \\
\hline
\end{tabular}

Fig. 20. Rasgos característicos de las fábricas de tapia en el Antiguo Reino de Sevilla (s. XII-XV).

El resto de los parámetros son circunstanciales, ya que se trata de rasgos muy variables o con escasas evidencias, lo que dificulta su evaluación y por lo tanto, de momento no pueden ser asociados a periodos históricos.

Según los datos de la figura 20 , una clásica fábrica de tapia almohade corresponde a una estructura monolítica en lienzos y verdugada en torres; los cajones tienden a ser bajos $(80-85 \mathrm{~cm})$; la capa de mortero entre las hiladas de tapias no existe o es muy delgada; presenta pares de agujas planas ( $7 \times 3 \mathrm{~cm}$, aproximadamente) y $\sin$ remate pétreo o latericio sobre las mismas; la separación de las agujas llega a ser más reducida que en periodos históricos posteriores $(35-45 \mathrm{~cm})$ y su ritmo, aunque puede ser continuo, se caracteriza porque presenta agrupaciones en secuencias de cuatro.

A partir de la figura 20, es posible definir con mayor exactitud la cronología de las fábricas sin vinculación cronológica. Así, en ocho de los trece casos de cronología 
incierta es posible establecer algunas hipótesis que apoyan el origen islámico o cristiano de las tapias. En cualquier caso se trata de planteamientos no definitivos, ya que solo establecen que los rasgos son más propios de alguna de los periodos, por lo que se deberían contrastar mediante estudios documentales o arqueológicos complementarios.

En cuanto a las fábricas de posible origen cristiano, la Torre de la Corchuela presenta sólidos indicios constructivos para pensar que es de factura cristiana. Las secciones cuadradas $(10 \mathrm{~cm} \times 10 \mathrm{~cm})$ de sus agujas y sus mechinales pasantes con remates de ladrillo representan rasgos constructivos impropios de los almohades en Andalucía Occidental y por el contrario se encuentran en numerosas fábricas cristianas, como las del Castillo de Luna (Mairena del Alcor) o la Ermita de Castilleja de Talhara (siglo XV, Benacazón). Además, el resto de los parámetros característicos son compatibles con un origen cristiano; su fábrica es monolítica, el módulo del cajón es alto y la secuencia de las agujas es continua. Por otro lado, la fábrica mixta de encadenados de piedra y verdugadas de ladrillo de la Torre de la Membrillera constituye un rasgo distintivo cristiano, como así sostienen Graciani y Tabales (2008). Asimismo, el resto de sus parámetros característicos vuelven a ser compatibles con fábricas del XIV-XV (remate de ladrillo en los mechinales, módulo alto o agujas planas).

Aunque los lienzos del Patio de la Sima del Castillo de Alcalá de Guadaíra muestran rasgos híbridos con ambos periodos, la secuencia de las agujas es totalmente inusual para una fábrica almohade. Las agrupaciones de 4 agujas totalmente ordenadas, además de las marcas de los encofrados, podrían ser indicios de una fábrica cristiana. Pudo haber sido realizado con mano de obra musulmana pero en un periodo de transición menos conflictivo, como sostiene García Fitz (2008), lo que posibilitaría una ejecución menos apresurada y mejor ejecutada como la que se muestra.

La torre de los Quintos presenta una situación especial, ya que los hilos inferiores muestran rasgos constructivos diferentes a los superiores, lo que podría indicar una ampliación cristiana debido al empleo de una pieza de remate sobre las agujas, a la verdugada de ladrillo que separa cada sector y a la diferente coloración de las tapias. Sin embargo, las agujas se encuentran menos distanciadas $(35 \mathrm{~cm})$ como ocurre en otras fábricas almohades, y los dos cuerpos comparten muchos rasgos comunes. Por todo ello, estas sutiles diferencias podrían responder a una simple reparación o refuerzo de la torre de mediados del s. XIII o bien durante las primeras décadas de la dominación cristiana.

Como se observa, ciertas innovaciones técnicas marcan las diferencias entre las fábricas cristianas e islámicas. Sin embargo, asignar una datación antes de mediados del s. XIII es más comprometido pues muchos recursos islámicos se seguirán empleando en época cristiana. Así, la Torre de la Dehesilla reúne rasgos compatibles con lo almohade, pero ninguna innovación cristiana: la fábrica es monolítica, emplea dos medias agujas planas sin remates, la secuencia de las agujas forma secuencias de cuatro desordenadas, como en los Castillos de Lora, Sanlúcar la Mayor o Niebla. Además, su módulo es corto $(80-85 \mathrm{~cm})$, y aunque es un parámetro muy variable, suele responder a fábricas más antiguas. Por todo ello se podría afirmar que es almohade. Por razones similares, el Castillo de Tejada la Vieja responde a una técnica de rasgos más islámicos, salvo por su módulo alto $(85-90 \mathrm{~cm})$, que es muy empleado en ambos periodos. Por último, los castillos de las Guardas y de Hornachos y la Torre de los Quintos, con módulos cortos, como único parámetro diferenciador junto a otros rasgos afines almohades, (pares de agujas planas con secuencias continuos, sin remates y sin mortero en las juntas) indican fábricas del s. XIII.

Aunque la conquista cristiana supuso un rápido cambio de poder, no fue así en las costumbres constructivas, que como muchas otras cuestiones administrativas, políticas o sociales tuvieron una clara continuidad. Sin embargo, este análisis demuestra la existencia de ciertos rasgos característicos constructivos ligados a etapas históricas y que por lo tanto pueden servir para datar y caracterizar la fábrica de tapia militar, aunque consideramos que, aun siendo argumentos sólidos, deben examinarse junto con otras evidencias históricas, documentales o arqueológicas.

\section{AGRADECIMIENTOS}

Este trabajo fue llevado a cabo en el marco del Proyecto de Investigación y Desarrollo (2004-2008) BIA200401092, titulado "Propuestas de mantenimiento, evaluación y restauración para la rehabilitación de edificios e infraestructuras urbanas de fábricas históricas de tapia en la Provincia de Sevilla (España)", dirigido por la Dra. A. Graciani García, en el marco del Plan Nacional de Investigación del Ministerio de Economía y Competitividad. 


\section{BIBLIOGRAFÍA}

Acién Almansa, M. 1995: "La fortificación en al-Andalus", en R. López Guzmán (coord.), La Arquitectura del Islam Occidental, pp. 29-41. Lunwerg, Barcelona.

Aguilar Moya, L. 2000: "Nuevos datos sobre las murallas islámicas de Jerez de la Frontera", Revista de Historia de Jerez, 6, pp. 99-114.

Almagro Gorbea, A. 2013: "Los palacios de Pedro I. La arquitectura al servicio del poder", Anales de Historia del Arte, 23, pp. 25-49.

Azuar Ruiz, R. (coord.) 1994: El castillo del Río (Aspe, Alicante): arqueología de un asentamiento andalusí y la transición al feudalismo (siglos XIIXIII), Colección Excavaciones Arqueológicas-Memorias, 2. Diputación Provincial de Alicante, Alicante.

Azuar Ruiz, R. 1995: "Las técnicas constructivas en al-Ándalus. El origen de la sillería y del hormigón de tapial”, en J. I. de la Iglesia Duarte (coord.), Actas de las V Semana de estudios medievales, pp. 125-142. Instituto de Estudios Riojanos, Nájera. Semana de Estudios Medievales, 1994, Nájera.

Azuar Ruiz, R., Llopis García, M. ${ }^{a}$ T., Lozano Olivares, F. J. y Menéndez Fuello, J. L. 1998: "El falso despiece de sillería en las fortificaciones de tapial en época almohade en al-Ándalus", en Actas del I Congreso de Castellología Ibérica, pp. 481-512, Diputación Provincial de Palencia, Palencia. I Congreso de Castellología Ibérica, 1994, Aguilar de Campoó (Palencia).

Azuar Ruiz, R. 2004: “Técnicas constructivas y fortificación almohade en alAndalus", en M. Valor Piechotta, J. L. Villar Iglesias, y J. Ramírez del Río (eds.), Los almohades: Su patrimonio arquitectónico y arqueológico en el Sur de al-Andalus, pp. 57-74. Consejería de Relaciones Institucionales de la Junta de Andalucía, Sevilla.

Azuar Ruiz, R. 2005: "Las técnicas constructivas en la formación de alAndalus", Arqueología de la Arquitectura, 4, pp. 149-160.

Barrios Padura, Á., Graciani García, A. y Núñez Arce, L. A. 2012: “Characterization of the rammed-earth structure of the Moon Castle in Mairena del Alcor (Seville, Spain)", en C. Mileto, F. Vegas y V. Cristini (eds.), Rammed Earth Conservation, pp. 263-267. Taylor y Francis Group, London. International Congress on Rammed Earth Conservation, 2012, Valencia.

Bazzana, A. 1980: "Eléments d'archéologie musulmane dans al-Andalus: caractères spécifiques de l'architecture militaire arabe de la region valencienne", Al-qantara: Revista de Estudios Árabes, I, pp. 339-364.

Bellido Márquez, T. 2008a: “Análisis estratigráfico en la muralla medieval de Marchena (Sevilla)", Arqueología de la Arquitectura, 5, pp. 159-185.

Bellido Márquez, T. 2008b: "La muralla medieval de Marchena: análisis arqueológico", Rómula, 7, pp. 299-330.

Canivell, J. 2012: "Characterization methodology to efficiently manage the conservation of historical rammed-earth buildings", en C. Mileto, F. Vegas y V. Cristini (eds.), Rammed Earth Conservation, pp. 283-288, Taylor y Francis Group, London. International Congress on Rammed Earth Conservation, 2012, Valencia.

Canivell, J., y González Serrano, A. 2012: "Muralla de Niebla: Un caso de estudio para la conservación del patrimonio monumental andaluz", en J. Vargas-Neumann, M. Blondet y D. Torrealva (eds.), Actas de XI Conferencia Internacional sobre el Estudio y Conservación del Patrimonio Arquitectónico de Tierra, Terra 2012, (CD). Pontificia Universidad Católica del Perú, Lima.

Canivell, J. y Graciani García, A. 2012: "Critical analysis of interventions in historical rammed-earth walls. Military buildings in the ancient Kingdom of Seville", en C. Mileto, F. Vegas y V. Cristini (eds.), Rammed Earth Conservation, Rammed Earth Conservation, pp. 289-295, Taylor y Francis Group, London. International Congress on Rammed Earth Conservation, 2012, Valencia.

Catarino, H. 1997: "Castelos muçulmanos do Algarve", en 90 séculos entre a serra e o mar, pp. 449-457. IPPAR, Lisboa.

Climent Simón, J. M., Gandía Álvarez, E. y Giner García, M. I. 2011: "Torres y murallas de la segunda albacara del Castillo de Cullera”, en S. Huerta Fernández (coord.), Actas del Séptimo Congreso Nacional de Historia de la Construcción, pp. 263-272. Instituto Juan de Herrera, Madrid. Séptimo Congreso Nacional de Historia de la Construcción, 2011, Santiago de Compostela.
Cressier, P., Fierro, M. y Molina, L. (eds.) 2005: Los almohades: problemas y perspectivas, en Estudios árabes e islámicos. Monografías, 11, 2 v. Consejo Superior de Investigaciones Científicas, Madrid.

Cuchí i Burgos, A. 1996: "La técnica tradicional del tapial", en A. de las Casas, S. Huerta Fernández y E. Rabasa (eds.), Actas del Primer Congreso Nacional de Historia de la Construcción, pp. 159-165. Instituto Juan de Herrera-CEHOPU, Madrid. Primer Congreso Nacional de Historia de la Construcción, 1996, Madrid.

Díaz Quidiello, J., Olmedo, F. y Clavero, M. Á. 2009: Atlas de la historia del territorio de Andalucía. Consejería de Vivienda y Ordenación del Territorio, Instituto de Cartografía de Andalucía, Sevilla.

Diputación Provincial de Palencia (ed.) 1998: Actas del I Congreso de Castellología Ibérica. 1994, Aguilar de Campoó (Palencia).

Doat, P., Hays, A., Houben, H., Matuk, S. y Vitoux, F. 1991: Building with earth. Editions Alternatives, Paris.

Font Mezquita, F. e Hidalgo i Chulio, P. 2009: Arquitecturas de tapia. Colegio Oficial de Aparejadores y Arquitectos Técnicos de Castellón, Castellón.

García de Cortázar, F. 2007: Atlas de historia de España, en J. M. Jover Zamora (ed.), Colección Historia de España Menéndez Pidal. Espasa-Calpe, Madrid.

García Fitz, F. 2008: "El castillo de Alcalá de Guadaíra (Sevilla): Estudio y fuentes documentales", Inventarios y catálogos. Ayuntamiento de Sevilla, vol. 6. Ayuntamiento de Sevilla, Sevilla.

Graciani García, A. 2005: "El proyecto I+D (2004-2007) BIA2004-01092: Propuestas de mantenimiento, evaluación y restauración para la rehabilitación de edificios e infraestructuras urbanas con fábricas históricas de tapial en la provincia de Sevilla", en Actas de las Jornadas de Investigación en Construcción, vol. 1, pp. 199-211, Instituto Eduardo Torroja (CSIC), Amiet, 2005, Madrid. I Jornadas de Investigación en Construcción, 2005, Madrid.

Graciani García, A. 2008: "Propuesta de metodología científica para la caracterización constructiva de fábricas de tapial en los estudios previos. Su aplicación a la Muralla de Sevilla en el tramo del Jardín del Valle”, en Actas del IX Congreso Internacional de Rehabilitación del Patrimonio Arquitectónico y Edificación, vol. 1, pp. 51-56, CICOP, International Centre for the Preservation of Architectural Heritage, Sevilla. IX Congreso Internacional de Rehabilitación del Patrimonio Arquitectónico y Edificación, 2008, Sevilla.

Graciani García, A. 2008-2009: "Fábricas islámicas del mirador almohade de la muralla de Marchena (Sevilla). Tramos de la Alcazaba y el Parque", Laboratorio de Arte 21, pp. 13-35.

Graciani García, A. 2009: "La técnica del tapial en Andalucía occidental", en Á. Suárez Márquez (coord.), Construir en al-Andalus, Monografías del Conjunto monumental de la Alcazaba, 2, pp. 111-140. Junta de Andalucía, Consejería de Cultura, Sevilla.

Graciani García, A., Tabales Rodríguez, M. Á., Alejandre Sánchez, F. J., Barrios Padura Á., Rodríguez García, R. y Ponce Ortiz de Insagurbe, M. 2005: "Revisión crítica de las analíticas sobre las fábricas de tapial en la muralla islámica de Sevilla”, en Actas de las Jornadas de Investigación en Construcción, vol. 1, pp. 213-222. Instituto Eduardo Torroja (CSIC), Amiet, 2005, Madrid. I Jornadas de Investigación en Construcción, 2005, Madrid.

Graciani García, A y Tabales Rodríguez, M. Á. 2008: "El tapial en el área sevillana. Avance cronotipológico estructural", Arqueología de la Arquitectura, 5, pp. 135-158.

Graciani García, A., Martín del Río, J. J., Mora Vicente, G.M., Alejandre Sánchez, F. J. y Canivell García de Paredes, J. 2012: "Preliminary studies for intervention, interpretation and value enhancement of Tower of Don Fadrique (Albaida, Seville, Spain)", en C. Mileto, F. Vegas y V. Cristini (eds.), Rammed Earth Conservation, Rammed Earth Conservation, pp. 345-350. Taylor y Francis Group, London. International Congress on Rammed Earth Conservation, 2012, Valencia.

Guerrero Misa, L. J. 1990: "Prospecciones arqueológicas de urgencia en el término municipal de Dos Hermanas (Sevilla), Anuario Arqueológico de Andalucía 1987, pp. 639-644. Consejería de Cultura de la Junta de Andalucía, Sevilla.

Gurriarán Daza, P., y Sáez Rodríguez, Á. J. 2002: “Tapial o fábricas encofradas en recintos urbanos andalusíes", Actas del II Congreso Internacional 
La Ciudad en al-Andalus y el Magreb, pp. 561-625. Fundación Legado Andalusí, Granada. II Congreso Internacional La Ciudad en al-Andalus y el Magreb, 1999, Algeciras (Cádiz).

Hernández Díaz, J., Sancho Corbacho, A. y Collantes de Terán, F. 1955: Catálogo arqueológico y artístico de la provincia de Sevilla, Diputación Provincial de Sevilla, Sevilla.

Iglesia Duarte, J. I. de la (coord.) 1995: Actas de las V Semana de estudios medievales, Instituto de Estudios Riojanos, Nájera. Semana de Estudios Medievales, 1994, Nájera.

Jaquin, P., Augarde, C., y Gerrard, C. 2008: "Chronological description of the spatial development of rammed earth techniques", en International Journal of Architectural Heritage, 2, pp. 377-400.

Jiménez Maqueda, D. 1996: “Algunas precisiones cronológicas acerca de la muralla de Sevilla", Laboratorio de Arte, 9, pp. 11-22.

Jiménez Maqueda, D. y Pérez Quesada, P. 2012: "La muralla huérfana. A vueltas con el último recinto amurallado de madnat Isblia", Romula, 12, pp. 273-347.

López Elum, P. J. 1994: La alquería islámica en Valencia. Estudio arqueológico de Bofilla, siglos XI-XIV. Generalitat Valenciana, Valencia.

López Martínez, F. J. 1996: "Tres experiencias de intervención sobre obras de tapia, en Murcia”, en Actas del III Congreso Internacional de Rehabilitación del Patrimonio Arquitectónico y Edificación, pp. 379-383. CICOP, International Centre for the Preservation of Architectural Heritage, Granada. III Congreso Internacional de Rehabilitación del Patrimonio Arquitectónico y Edificación, 1996. Granada.

López Martínez, F. J. 1999: “Tapias y tapiales”, Loggia: Arquitectura y Restauración, 8, pp. 74-89.

López Martínez, F. J. 2012: "Restoration of rammed earth structures", en C. Mileto, F. Vegas y V. Cristini (eds.), Rammed Earth Conservation, pp. 2126. Taylor y Francis Group, London. International Congress on Rammed Earth Conservation, 2012, Valencia.

López Osorio, J. M. 2012: "The Nasrid ramparts of the Albaicín (Granada, Spain): An analysis of materials and building techniques", en C. Mileto, F. Vegas y V. Cristini (eds.), Rammed Earth Conservation, pp. 27-32. Taylor y Francis Group, London. International Congress on Rammed Earth Conservation, 2012, Valencia.

Lozano Olivares, F. J., Menéndez Fuello, J. L., Azuar Ruiz, R. y Llopis García, M. a T. 1996: "El falso despiece de sillería en las fortificaciones de tapial en época almohade en al-Ándalus", Estudios de historia y de arqueología medievales 11, pp. 245-278.

Maldonado Ramos, L. y Vela-Cossío, F. 2011: "The earthen architectural heritage. Historiographical contributions and the appreciation of its values in the context of the Spanish popular architecture", Informes de la Construcción, 63, 523, pp. 71-80.

Malpica Cuello, A. 2003: Los Castillos en al-Andalus y la organización del territorio. Universidad de Extremadura, Cáceres.

Márquez Bueno, S. y Gurriarán Daza, P. 2008: "Recursos formales y constructivos en la arquitectura militar almohade de al-Andalus", Arqueología de la Arquitectura, 5, pp. 115-134.

Martín García, M. 2005: "La construcción del tapial en época nazarí: el caso de la muralla exterior del Albaicín de Granada", en S. Huerta Fernández (ed.), Actas del Cuarto Congreso Nacional de Historia de la Construcción, vol. 2, pp. 741-749. Instituto Juan de Herrera, Madrid. Cuarto Congreso Nacional de Historia de la Construcción, 2005, Cádiz.

Martín García, M. y Martín Civantos, J. M. 2011: “Técnicas y tipologías constructivas de las fortificaciones medievales del poniente almeriense", en S. Huerta Fernández, I. Gil Crespo, S. García y M. Taín (eds.), Actas del Séptimo Congreso Nacional de Historia de la Construcción, vol. 2, pp.
851-860. Instituto Juan de Herrera, Madrid. Séptimo Congreso Nacional de Historia de la Construcción, 2011, Santiago de Compostela.

Mileto, C., Vegas López-Manzanares, F. y López Osorio, J. M. 2011: “Criteria and intervention techniques in rammed earth structures: The restoration of Bofilla tower at Bétera (Valencia)", Informes de la Construcción, 63, 523: pp. 81-96.

Mileto, C., Vegas López-Manzanares, F., Cristini, V. y García Soriano, L. 2012: "Restoration of rammed earth architecture in the Iberian Peninsula: Ongoing research", en C. Mileto, F. Vegas y V. Cristini (eds.), Rammed Earth Conservation, pp. 381-386. Taylor y Francis Group, London. International Congress on Rammed Earth Conservation, 2012, Valencia.

Ontiveros Ortega, E., Valverde Espinosa, I. y Sebastián Pardo, E. 1996: "Técnicas de análisis aplicadas al estudio de los tapiales de las murallas de Granada", en Actas del III Congreso Internacional de Rehabilitación del Patrimonio Arquitectónico y Edificación, pp. 270-273. CICOP, International Centre for the Preservation of Architectural Heritage, Granada. III Congreso Internacional de Rehabilitación del Patrimonio Arquitectónico y Edificación, 1996. Granada.

Ontiveros Ortega, E. (coord.), Valverde Espinosa, I. y Sebastián Pardo, E. 2006: Programa de normalización de estudios previos aplicado a bienes inmueble, Cuadernos PH 19, Consejería de Cultura de la Junta de Andalucía, Instituto Andaluz de Patrimonio Histórico, Sevilla.

Pérez Macías, J. A., Campos Carrasco, J. M. y Gómez Toscano, F. 2000: "Niebla, de oppidum a madina", Anales de Arqueología Cordobesa, 11, pp. 91-122.

Soler Estrela, A. 2009: "La técnica del tapial en las fortificaciones y despoblados de Sharq al-Andalus. Un estudio arquitectónico constructivo", en S. Huerta, R. Marín Sánchez y R. Soler Verdú (eds.), Actas del Sexto Congreso Nacional de Historia de la Construcción, pp. 1361-1370. Instituto Juan de Herrera, Madrid. Sexto Congreso Nacional de Historia de la Construcción, 2009, Valencia.

Torre López, M. J. de la; Sebastián Pardo, E. y Rodríguez Gordillo, J. 1996: "A study of the wall material in the Alhambra (Granada, Spain)", en $\mathrm{Ce}$ ment and Concrete Research, 26, 6, pp. 825-839.

Torres Balbás, L. 1960a: “Aznalfarache = Hisn al-Faray”, Al-Andalus, 25, 1, p. 222.

Torres Balbás, L. 1960b: "Las puertas en recodo en la arquitectura militar hispanomusulmana", Al-Andalus, XLVIII, pp. 419-441.

Ubieto Arteta, A. 1984: Génesis y desarrollo de España. Instituto de Ciencias de la Educación de la Universidad de Zaragoza, Zaragoza.

Utrera Burgal, R. y Tabales Rodríguez, M. Á. 2009: "El castillo de San Romualdo (San Fernando, Cádiz). Aproximación estratigráfica y evolución constructiva", Arqueología de la Arquitectura, 6: pp. 245-265.

Valor Piechotta, M. 2004a: "Algunos ejemplos de construcciones defensivas almohades en la provincia de Sevilla”, en M. Valor Piechotta, J. L. Villar Iglesias y J. Ramírez del Río (eds.), Los almohades: Su patrimonio arquitectónico y arqueológico en el Sur de al-Andalus, pp. 145-179. Consejería de Relaciones Institucionales de la Junta de Andalucía, Sevilla.

Valor Piechotta, M. 2004b: "Las fortificaciones de la Baja Edad Media en la Provincia de Sevilla", Historia, Instituciones, Documentos, 31, pp. 687-700.

Valverde Espinosa, I., Ontiveros Ortega, E. y Sebastián Pardo, E. 1997: “El tapial de las murallas de Granada", Revista Edificación, 26, pp. 58-63.

Vigueras Molins, M. J. 2004: "Espacio y construcciones en textos almohades”, en M. Valor Piechotta, J. L. Villar Iglesias y J. Ramírez del Río (eds.), Los almohades: Su patrimonio arquitectónico y arqueológico en el Sur de al-Andalus, pp. 9-24. Consejería de Relaciones Institucionales de la Junta de Andalucía, Sevilla. 